\title{
Numerical Study on the Autoignition of Biogas in Moderate or Intense Low Oxygen Dilution Nonpremixed Combustion Systems
}

\author{
Aromal Vasavan,*i( Philip de Goey, and Jeroen van Oijen \\ Multiphase and Reactive Flows Group, Mechanical Engineering Department, Eindhoven University of Technology, 5600 MB \\ Eindhoven, Netherlands
}

Supporting Information

\begin{abstract}
The ignition delay of biogas in mixing layers is investigated using a one-dimensional combustion model, with its application in Moderate or Intense Low oxygen Dilution (MILD) combustion being the focus. The current study reveals the key aspects of the ignition of biogas in a nonpremixed, igniting mixing layer with a hot oxidizer of low oxygen content. The observed characteristics are contrasted against the existing studies on ignition in homogeneous mixtures under similar conditions. Biogas is considered here as a mixture of $\mathrm{CH}_{4}$ with variable amounts $\mathrm{CO}_{2}$. The influence of reactive, thermal, and transport properties of $\mathrm{CO}_{2}$ on the ignition is evaluated using artificial species to mimic the respective characteristics of $\mathrm{CO}_{2}$. While the ignition delay in homogeneous mixtures shows a strong dependence on $\mathrm{CO}_{2}$ content in the fuel, the ignition delay predictions from one-dimensional mixing layers show no significant influence of $\mathrm{CO}_{2}$ levels in biogas. In addition, the influence of oxidizer composition and temperature on ignition delay is determined for $\mathrm{CO}_{2}$ levels ranging from $0 \%$ to $90 \%$. A sensitivity analysis of chemical reactions on the ignition delay shows a negligible effect of $\mathrm{CO}_{2}$ concentration in biogas. The current study emphasizes the role of oxidizer composition and temperature on the ignition characteristics of a MILD biogas flame.
\end{abstract}

\section{INTRODUCTION}

Biogas can be considered as a carbon neutral fuel when it has its origins in the anaerobic digestion of organic matter by living organisms. The major components that make up biogas are methane and $\mathrm{CO}_{2}$. Due to the presence of a considerable amount of $\mathrm{CO}_{2}$, biogas has a low calorific value. In spite of this, biogas is a promising candidate to meet the engergy targets set by the European Union due to its flexibility as an energy source and its wide range of applications including heating and electricity production. ${ }^{17}$ It is widely accepted to be a sustainable fuel for households as well as industrial applications despite challenges with production and implementation. ${ }^{5}$ Still, at present, its industrial applications are limited due to low heating value and variable composition of biogas often containing corrosive components such as $\mathrm{H}_{2} \mathrm{~S}^{18}$ It is not an easy task to ensure the production of biogas with a fixed composition by virtue of its biological origin. The variation in the composition of biogas coupled with its low heat release rate could reduce the thermal efficiency of engines. ${ }^{3}$ The application of biogas in engines was reviewed in ref 31 . For engine relevant conditions, the ignition delay trend with respect to $\mathrm{CO}_{2}$ level has been predicted from the studies on ignition of homogeneous mixtures of biogas with air, ${ }^{40}$ given that in engine applications biogas is premixed with air. However, for the ignition of biogas in nonpremixed systems where the fuel and oxidizer are initially separated, only limited literature is available to the authors' knowledge. It is therefore important to extend our knowledge on the influence of biogas composition changes in nonpremixed systems.

For applications such as fueling industrial furnaces, the environmental impact of exhaust gases is a major concern provided that there is a considerable amount of NOx released from conventional burners and so is the carbon footprint left by the fuel consumption. ${ }^{24}$ Moderate or intense low oxygen dilution (MILD) combustion has been a subject in a number of studies for its potential to deliver high thermal efficiency with lower pollutant emissions. ${ }^{4,9,26}$ For achieving MILD combustion, the gas flow has to be kept above the autoignition temperature of the fuel. The fuel is burned under strong mixing in a hot, low oxygen environment. The heat release rate of combustion can be lower than that of conventional feed-back stabilized combustion, provided a hot-diluted environment is maintained. Hence furnaces operating in MILD mode can run on fuels such as biogas with a low heat content. The peak temperatures attained are lower than conventional burners, which yields a substantial reduction in the thermally generated $\mathrm{NO}_{x}{ }^{39}$ MILD combustion is materialized in practical burners of various configurations $\mathrm{s}^{6,7,10,11}$ that differ in flame structures and stabilization mechanism. MILD combustion of biogas has been studied using the Delft Jet-in-Hot-Coflow (DJHC) burner, which is a laboratory scale burner that mimics MILD combustion conditions where the fuel jet is issued into a hot coflow of lean combustion products. ${ }^{26}$ Oldenhof et al. ${ }^{25,28}$ performed experiments on the DJHC burner with natural gas as the fuel, and Sarras et al. ${ }^{32}$ studied the influence of mixing $\mathrm{CO}_{2}$ with natural gas. The combination of $\mathrm{CO}_{2}$ and natural gas mimics biogas, except for the presence of trace amounts of ethane and higher alkanes in natural gas. From these studies, the stabilization of JHC flames is found to be dependent on the formation and propagation of autoignition kernels. The ignition delay for methane diluted with $\mathrm{CO}_{2}$ was experimentally measured for homogeneous mixtures with air by

Received: April 20, 2018

Revised: July 11, 2018

Published: July 21, 2018 
Zeng et al. ${ }^{40}$ Their study focused on the ignition of mixtures with equivalence ratios of $0.5,1$, and 2 , for a temperature range of $1300-2100 \mathrm{~K}$ and pressure range of $0.1-1 \mathrm{MPa}$. It was shown that an increase in dilution by $\mathrm{CO}_{2}$ or $\mathrm{N}_{2}$ has an inhibitory effect on ignition delays at every equivalence ratio. This effect is stronger for dilution with $\mathrm{CO}_{2}$ than $\mathrm{N}_{2}$. Their numerical investigation showed that the ignition of methane/ air mixtures is sensitive to reactions involving $\mathrm{H}, \mathrm{O}$, and $\mathrm{OH}$ radicals. With increase in $\mathrm{CO}_{2}$ or $\mathrm{N}_{2}$ in the mixture, reactions promoting the ignition were found to be inhibited. Fischer and Jiang ${ }^{14}$ performed a computational study on the ignition of homogeneous $\mathrm{CH}_{4}-\mathrm{CO}_{2}-\mathrm{O}_{2}$ mixtures and compared the ignition delays predicted by five different reaction mechanisms against the results from shock tube experiments. Their study showed that among the five, GRI Mech $3.0^{34}$ delivered the best predictions for the ignition delays of $\mathrm{CH}_{4}-\mathrm{CO}_{2}$ mixtures.

It has to be realized that in a JHC burner the reactants are not premixed. A DNS study on the fine structure of turbulent MILD combustion of methane by Doan et al. ${ }^{12}$ has shown that the nonpremixed combustion mode is relevant even if the initial mixture is partially premixed. Hence, studies on MILD flames under nonpremixed conditions become necessary to understand their ignition and combustion behavior. ${ }^{8}$ Sidey and Mastorakos ${ }^{33}$ studied the effect of adding $\mathrm{CO}_{2}$ with methane in steady diffusion flames under MILD conditions. The effect of strain rate on the flame structure and maximum temperature was studied along with the extinction behavior. Wang et al. ${ }^{38}$ investigated the chemical and physical aspects of adding $\mathrm{CO}_{2}$ to $\mathrm{CH}_{4}$ in steady counterflow diffusion flames. The $\mathrm{CO}_{2}$ presence was found to reduce the flame temperatures and increase the $\mathrm{CO}$ production by reducing its rate of oxidation into $\mathrm{CO}_{2}$. These studies on steady diffusion flames provide insights regarding the flame structures, flame quenching, and pollutant formation and help in understanding the interplay of chemistry in MILD nonpremixed flames. However, the ignition in nonpremixed systems was not clearly addressed here which is a key aspect in the flame stabilization in MILD burners.

A one-dimensional Igniting Mixing Layer (IML) $)^{1,22,37}$ serves as the simplest physical representation of a nonpremixed system. The present study aims at investigating the ignition of methane and biogas under MILD conditions through IML simulations. The range of boundary conditions applied in the current study is based on the Delft JHC studies with Dutch Natural Gas (DNG) ${ }^{26}$ and biogaslike fuels. ${ }^{34}$ It was found in ref 34 that addition of $\mathrm{CO}_{2}$ did not result in a considerable change of the lift-off height of a natural gas flame, which seems to contradict the findings from studies on homogeneous mixtures where $\mathrm{CO}_{2}$ affects the ignition delays substantially. It was further suggested that the addition of $\mathrm{CO}_{2}$ to natural gas in a JHC may result in a counteracting mechanism of slower ignition chemistry against the increased turbulent entrainment of a hot oxidizer, that maintains the lift-off heights at the same level. The influence of $\mathrm{CO}_{2}$ on ignition is also addressed in the current study. The main objectives of this study are summarized as

- To study the ignition and flame development in an IML and to identify the most sensitive reactions that influence the ignition delay;

- To investigate the effects of $\mathrm{CO}_{2}$ content in the fuel on ignition delay of methane/natural gas and to assess the influence of thermochemical properties of $\mathrm{CO}_{2}$ on biogas ignition;
- To examine the dependence of ignition delay on the oxidizer temperature and oxygen level for $\mathrm{CH}_{4}$ and $\mathrm{CH}_{4}-\mathrm{CO}_{2}$ mixtures.

In the following section the computational methodology is presented, the results of IML simulations are discussed next, along with the inferences from sensitivity analysis, followed by the conclusions from the study.

\section{COMPUTATIONAL METHOD}

The physical and chemical processes in a MILD flame (e.g., $\mathrm{JHC}$ ) are very similar to those in an IML. An IML is a timedependent reaction-diffusion layer, ${ }^{1,19,37}$ where the diffusive transport and reactive processes occur simultaneously from an initial unmixed state, which represents a pocket of fuel issuing from the jet and mixing with the hot oxidizer, leading to its ignition. As shown in Figure 1, at time $t=0$ for $x<0$ the local

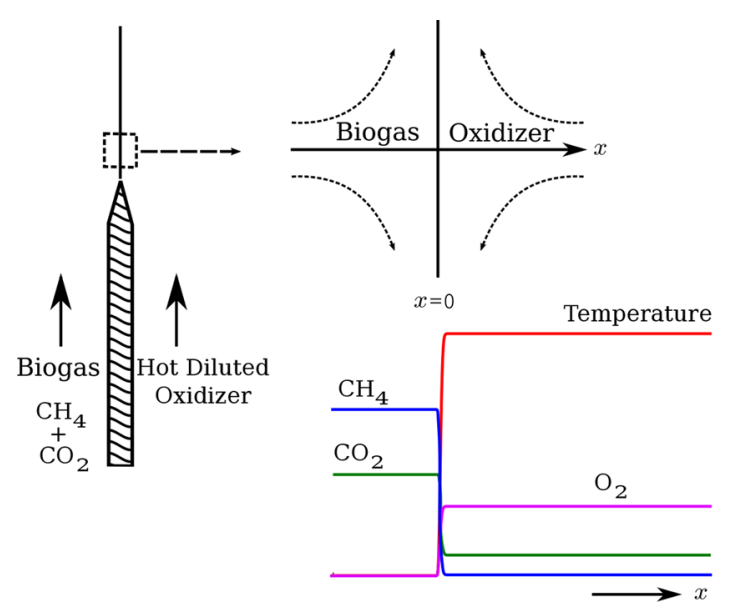

Figure 1. Schematic diagram of the case setup for IML, representing the initial profiles of the major species and temperature.

thermochemical properties describe the fuel flow and for $x>0$ they correspond to the oxidizer conditions. Due to the steep initial gradients in concentration of fuel and oxidizer, in the absence of an applied strain, the mixing is governed entirely by diffusive fluxes. The scalar gradients dissipate with time and the reactive-diffusive processes asymptotically approach a state of chemical equilibrium at $t \rightarrow \infty$. In the present study, IML is modeled as a time-dependent $1 \mathrm{D}$ counterflow flame with a low strain rate $\left(a=10 \mathrm{~s}^{-1}\right)$. That is, from an initially unmixed state, the mixing layer approaches a steady state counterflow flame with $a=10 \mathrm{~s}^{-1}$. The application of strain rate makes it possible to keep the flame within a physical domain of finite size and to achieve a steady state condition in approximately $1 \mathrm{~s}$. This approach is different from an Igniting Counterflow Flame $(\mathrm{ICF})^{20}$ where the reactive process starts from a steady nonreacting counterflow solution with an applied strain rate, where the time-dependent changes in scalar dissipation rate is not considered. An IML is expected to mimic a MILD flame than ICF for this reason. The transport equations that describe a one-dimensional unsteady counterflow are given by ${ }^{15}$

$$
\begin{aligned}
& \frac{\partial \rho}{\partial t}+\frac{\partial \rho u}{\partial x}=-\rho G \\
& \rho \frac{\partial Y_{i}}{\partial t}+\rho u \frac{\partial Y_{i}}{\partial x}-\frac{\partial}{\partial x}\left(\rho U_{i} \frac{\partial Y_{i}}{\partial x}\right)-\dot{w}_{i}=0
\end{aligned}
$$




$$
\begin{gathered}
\rho \frac{\partial h}{\partial t}+\rho u \frac{\partial h}{\partial x}-\frac{\partial}{\partial x}\left(\frac{\lambda}{c_{p}} \frac{\partial h}{\partial x}\right) \\
=\frac{\partial}{\partial x}\left(\sum_{i=1}^{N_{\mathrm{sp}}} h_{i}\left(\rho Y_{i} U_{i}-\frac{\lambda}{c_{p}} \frac{\partial Y_{i}}{\partial x}\right)\right)
\end{gathered}
$$

where $\rho, c_{p}, \lambda$, and $\mu$ stand for mass density, specific heat at constant pressure, thermal conductivity, and viscosity, respectively. $U_{i}$ represents the diffusion velocity, and $u$, the velocity in $x$ direction. $Y_{i}$ and $\dot{w}_{i}$ are the mass fraction and chemical production rate $\left(\mathrm{kg} / \mathrm{m}^{3} \cdot \mathrm{s}\right)$ of the $i$ th species where $i$ ranges from 1 to $N_{\mathrm{sp}}$, the total number of species. The momentum balance in counterflow configuration is modeled after Dixon-Lewis ${ }^{15}$ through solving a transport equation for $G$ (eq 4), the tangential velocity gradient or strain rate:

$$
\rho \frac{\partial G}{\partial t}+\rho u \frac{\partial G}{\partial x}-\frac{\partial}{\partial x}\left(\mu \frac{\partial G}{\partial x}\right)=J-\rho G^{2}
$$

Here $J=\rho_{\text {ox }} a^{2}$, with $a$ being the applied strain rate and $\rho_{\text {ox }}$ the density at the oxidizer side. The computational time is set to $1 \mathrm{~s}$ within which the flame attains a near steady state. It is assumed that the hot diluted oxidizer is at chemical equilibrium. The oxidizer composition is computed as a constrained chemical equilibrium solution for a given temperature and oxygen level.

In theory, the initial condition for IML can be modeled as a Heaviside function. However, the numerical scheme for resolving diffusive fluxes uses a finite spatial and temporal spacing. Therefore, the Heaviside solution is replaced with a smooth initial condition obtained from a steady counterflow solution with a high applied strain which approximates a Heaviside function. In the current case the initial condition is computed as a steady counterflow solution with $a=10^{4} \mathrm{~s}^{-1}$. This applied strain rate is sufficiently high, so that the flame is quenched and initial the mixing layer thickness is of the order of $100 \mu \mathrm{m}$. Subsequently, the strain rate $G(x)$ is rescaled based on $a=10 \mathrm{~s}^{-1}$ and the corresponding mass flux $\rho u$ is updated for every grid point in the domain based on the steady state mass conservation

$$
\frac{\partial \rho u}{\partial x}=-\rho G
$$

Using the initial profile thus obtained, an unsteady simulation is performed using the one-dimensional flame code CHEM1D. ${ }^{35}$ The code uses adaptive mesh refinement in combination with variable time stepping. The results are verified to be independent of mesh size and time step size. For the analysis of the IML flamelets, Bilger's definition of mixture fraction $Z$ is used, which is given as

$$
\begin{aligned}
Z= & \left\{0.5 M_{\mathrm{H}}^{-1}\left[Z_{\mathrm{H}}-Z_{\mathrm{H}, 2}\right]+2 M_{\mathrm{C}}^{-1}\left[Z_{\mathrm{C}}-Z_{\mathrm{C}, 2}\right]\right. \\
& \left.-M_{\mathrm{O}}^{-1}\left[Z_{\mathrm{O}}-Z_{\mathrm{O}, 2}\right]\right\} /\left\{0.5 M_{\mathrm{H}}^{-1}\left[Z_{\mathrm{H}, 1}-Z_{\mathrm{H}, 2}\right]\right. \\
& \left.+2 M_{\mathrm{C}}^{-1}\left[Z_{\mathrm{C}, 1}-Z_{\mathrm{C}, 2}\right]-M_{\mathrm{O}}^{-1}\left[Z_{\mathrm{O}, 1}-Z_{\mathrm{O}, 2}\right]\right\}
\end{aligned}
$$

where $Z_{\mathrm{H}}, Z_{\mathrm{C}}$, and $Z_{\mathrm{O}}$ are the elemental mass fractions of hydrogen, carbon and oxygen, respectively. $M_{\mathrm{H}}, M_{\mathrm{C}}$, and $M_{\mathrm{O}}$ are the corresponding atomic masses.

A number of cases with varying fuel and oxidizer boundary conditions is simulated. Table 1 gives a concise overview of the computational set up. On the oxidizer side the temperature $T_{\text {ox }}$ is varied from $1200-1600 \mathrm{~K}$ and the oxygen level $\left(Y_{\mathrm{O}_{2}, \mathrm{ox}}\right)$ is
Table 1. Summary of Computational Setup

\begin{tabular}{ll}
\multicolumn{1}{c}{ parameter } & \multicolumn{1}{c}{ values } \\
$x$ range & {$[-1: 2.5] \mathrm{cm}$} \\
time step & variable time stepping $\left[10^{-8}: 10^{-4}\right] \mathrm{s}$ \\
number of grid points & 500 (with adaptive grid refinement) \\
fuel compostion $(\mathrm{mol})$ & $\left(1-X_{\mathrm{CO}_{2}}\right) \mathrm{CH}_{4}+X_{\mathrm{CO}_{2}} \mathrm{CO}_{2}$ \\
fuel temperature & $450 \mathrm{~K}$ \\
oxidizer composition & vitiated air with $Y_{\mathrm{O}_{2}, \mathrm{ox}}=0.04$ and 0.06 \\
& (details are available in the Supporting \\
& Information) \\
oxidizer temperature & 1200-1600 K \\
reaction mechanism & GRI-Mech 3.0 \\
transport model & mixture averaged
\end{tabular}

varied between $2 \%$ and $16 \%$ by mass as given in the Supporting Information. The ranges of $Y_{\mathrm{O}_{2}, \mathrm{ox}}$ and $T_{\mathrm{ox}}$ are chosen based on the oxygen percentage and temperature in the coflow of the DJHC experiments. ${ }^{27}$ The Supporting Information also gives the mass fractions of major species in the oxidizer and the stoichiometric mixture fraction $Z_{\mathrm{st}}$. The fuel is chosen as methane for the reference case, and for the biogas study, the $\mathrm{CO}_{2}$ mole fraction is increased from $0 \%$ to $90 \%$ with the rest being methane. The fuel temperature is chosen as $450 \mathrm{~K}$ for all simulations as observed in the DJHC burner. ${ }^{27}$ All simulations are performed at atmospheric pressure. A mixture-averaged diffusion transport model ${ }^{35}$ is used along with the GRI 3.0 mechanism for reaction chemistry. It was shown in multiple numerical studies that GRI 3.0 gives accurate predictions of ignition delay for biogaslike fuel combinations. ${ }^{14,40}$

\section{RESULTS AND DISCUSSION}

First, the characteristics of ignition in an IML are discussed and a comparison of IML is made against ICF. Further, the ignition delay trends for methane and biogas are estimated for a range of $\mathrm{CO}_{2}$ levels. The impact of $\mathrm{CO}_{2}$ on the ignition delay of biogas is assessed by introducing artificial species to isolate the effects of chemical, transport, and thermal properties of $\mathrm{CO}_{2}$. The impact of oxidizer composition and temperature are estimated thereafter. The sensitivity of ignition reactions to the amount of $\mathrm{CO}_{2}$ in biogas is analyzed under the IML configuration.

3.1. Structure of IML and Comparison with ICF. The evolution of a mixing layer from an unmixed initial condition toward a steady diffusion flame involves a series of mutually dependent chemical and thermal events under a continuously decaying scalar dissipation in the domain. This includes the preignition chemistry, ignition, and heat release followed by diffusive flame spreading. In Figure $2 \mathrm{a}$ the time-dependent mixture fraction $(Z)$ profiles from $t=0$ to $0.1 \mathrm{~s}$ in a $1 \mathrm{D}$ IML are shown. The fuel considered here is methane, and the oxidizer has $8 \% \mathrm{O}_{2}$ by mass and a temperature of $1540 \mathrm{~K}$. Figure 2 a shows the progressive mixing of the initially unmixed fuel and oxidizer, proceeding toward a well mixed state. During the mixing process the hot oxidizer reacts with the fuel releasing heat, and the corresponding temperature profiles are shown in Figure $2 \mathrm{~b}$. The temperature rise is defined as $\Delta T(Z$, $t)=T(Z, t)-T(Z, t=0)$. In Figure $2 c \Delta T(Z, t)$ is plotted against $Z$; it shows the temperature rise starting from a location with $Z$ close to 0 and growing to reach a maximum of $600 \mathrm{~K}$ near the stoichiometric mixture fraction, $Z_{\text {st }}=0.02$. The timedependent variation in the maximum temperature in the 


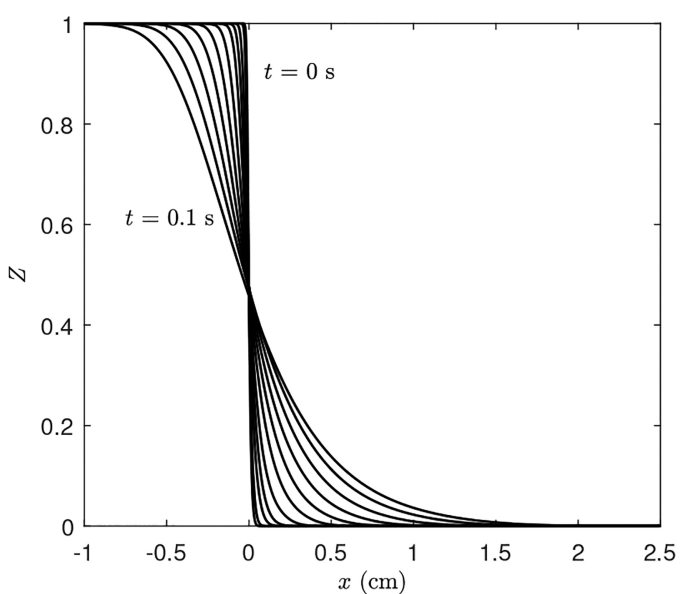

(a)

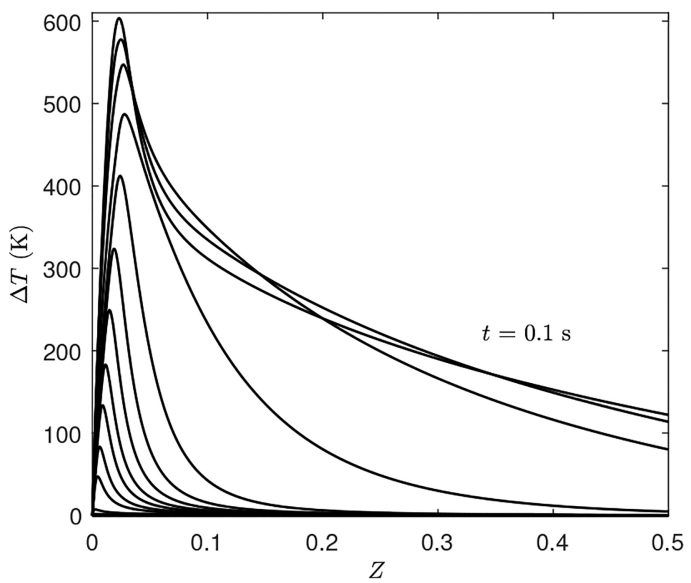

(c)

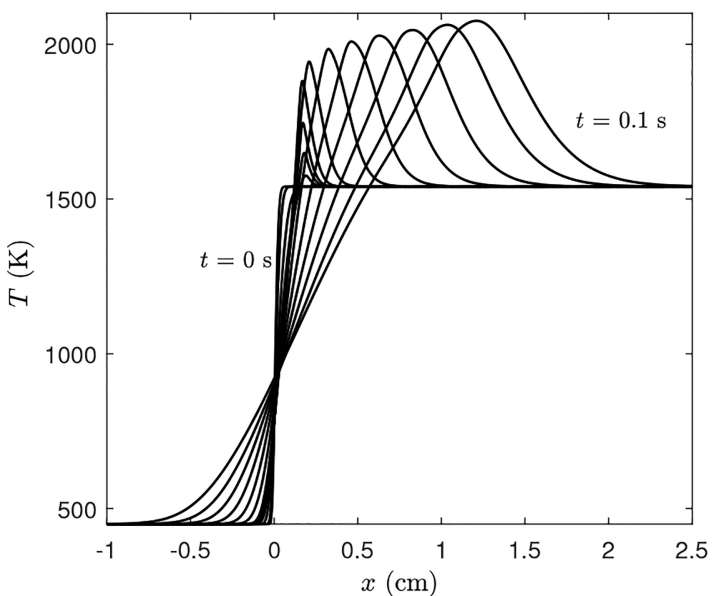

(b)

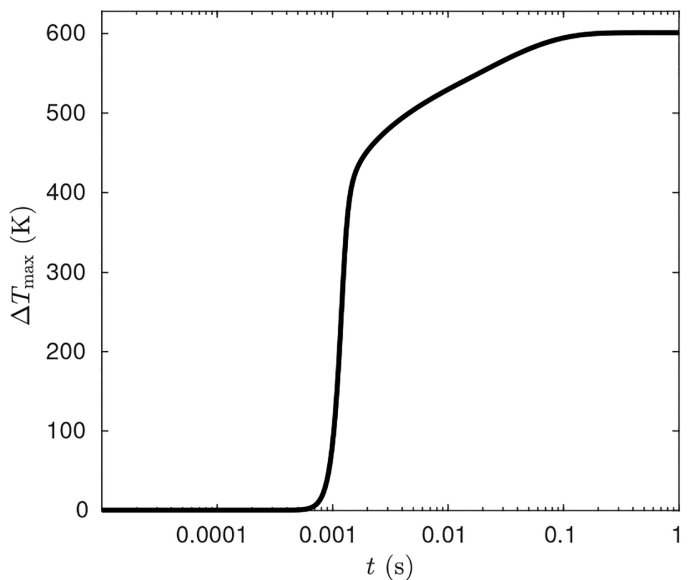

(d)

Figure 2. Time-dependent characteristics of IML: (a) mixture fraction, (b) temperature profiles, (c) temperature rise $\Delta T$ against $Z$, and (d) maximum temperature rise $\Delta T_{\max }$ against time $t$. Plots in a-c correspond to time $t=0-0.1 \mathrm{~s}$.

domain, $\Delta T_{\max }$ is shown in Figure $2 \mathrm{~d}$. It shows a preignition phase where the temperature rise is slow, up to $t \approx 10^{-3} \mathrm{~s}$, and thereafter, $\Delta T_{\max }$ shoots to a maximum of $\Delta T_{\max } \approx 600 \mathrm{~K}$ owing to a rapid heat release following ignition. Ignition delay under MILD conditions has shown good agreement with a temperature rise threshold of $10 \mathrm{~K}$ as it correlates well to the onset of chemiluminescence. ${ }^{13}$ Hence in this study the ignition delay $\left(\tau_{\mathrm{ig}}\right)$ is defined as the time for achieving $\Delta T_{\max }=10 \mathrm{~K}$. The value of $Z$ at which this $\Delta T_{\max }$ is attained is denoted as the most reactive mixture fraction, $Z_{\mathrm{mr}}$.

Autoignition in an IML is governed by reaction and diffusion processes. An unsteady diffusion flame with unity Lewis number is described by the unsteady flamelet equation for temperature as ${ }^{29}$

$$
\rho \frac{\partial T}{\partial t}=\dot{\omega}_{T}+\frac{1}{2} \rho \chi \frac{\partial^{2} T}{\partial Z^{2}}
$$

where $\dot{\omega}_{T}$ is the source term for temperature from the chemical reactions. The second term in the RHS corresponds to the diffusive transport, with $\chi$ being the scalar dissipation rate given by

$$
\chi=2 D\left(\frac{\partial Z}{\partial x}\right)^{2}
$$

where $D$ is the scalar diffusivity which is equal to $\frac{\lambda}{\rho c_{p}}$ for unity Lewis number. A high scalar dissipation delays ignition in nonpremixed systems. ${ }^{30}$ For an IML with a Heaviside initial condition, the expression for $\chi$ is obtained as ${ }^{29}$

$$
\chi_{\mathrm{th}}(Z, t)=\frac{1}{2 \pi t} e^{-2\left[\operatorname{erfc}^{-1}(2 Z)\right]^{2}}
$$

which indicates that $\chi \propto t^{-1}$. In order to understand the influence of $\chi$ on ignition, the IML under consideration is compared against an ICF with the same fuel and oxidizer boundary conditions and with a strain rate of $10 \mathrm{~s}^{-1}$. In Figure 3a the values of $\chi$ at $Z_{\mathrm{mr}}$ and $Z_{\mathrm{st}}$ are plotted against time for IML and ICF. Theoretically the values of $\chi$ in an IML approach infinity at $t=0$ as the mixing layer thickness, $\delta_{\mathrm{th}}$, is infinitesimally thin. In this $\log -\log$ plot, $\chi_{\text {th }}$ follows a straight line with negative slope starting from a magnitude that tends to infinity at $t=0$. In the current simulations, the mixing layer thickness $\delta$ varies from an initial value, $\delta_{Z \text {,initial }}=0.5 \mathrm{~mm}$ to $\delta_{Z, \text { final }}=25 \mathrm{~mm}$. Therefore, the initial values of $\chi$ are obtained 


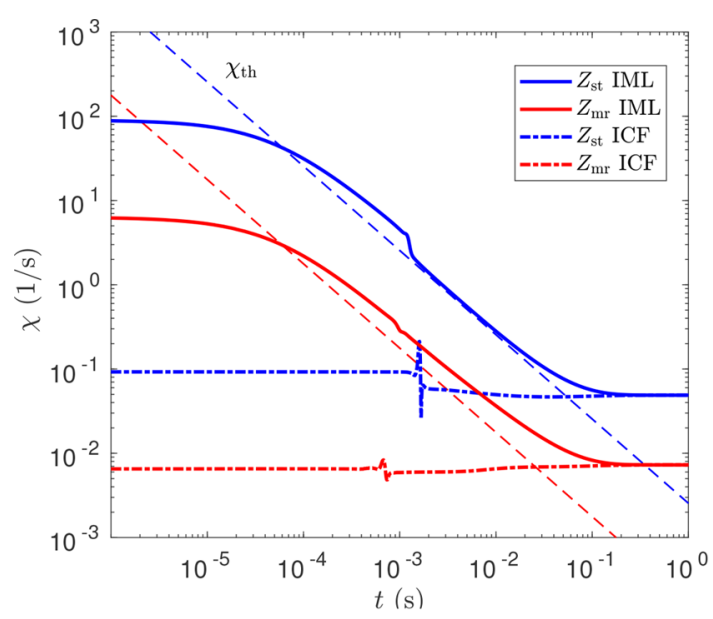

(a)

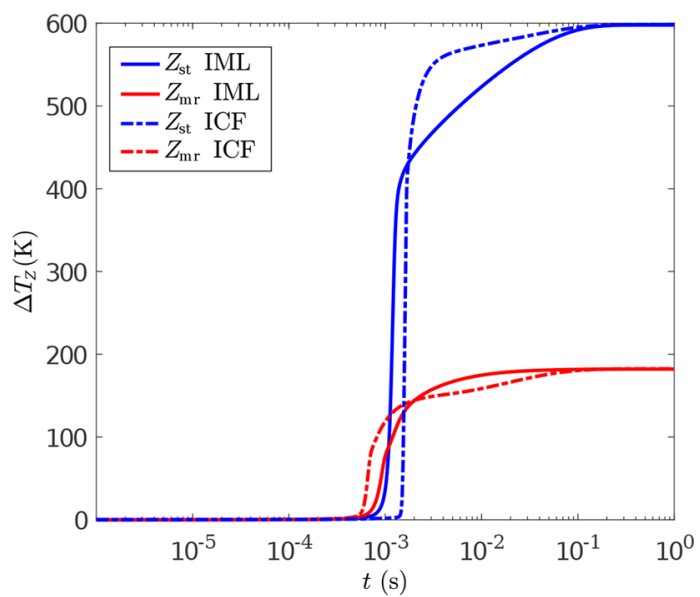

(b)

Figure 3. Scalar dissipation rates (a) and $\Delta T_{Z}$ (b) at $Z_{\mathrm{mr}}$ and $Z_{\mathrm{st}}$ against time for IML and ICF. The straight dashed lines in a indicate the "ideal" profile of $\chi_{\text {th }}$ against time.

to be finite and the final values are determined by the applied strain rate. The red and blue lines correspond to $Z_{\mathrm{mr}}$ and $Z_{\mathrm{st}}$ respectively. The IML closely follows the $\chi_{\text {th }}$ within the range of $\chi$ corresponding to $\delta_{Z \text {,initial }}$ and $\delta_{Z \text {,final }}$. The scalar dissipation trend in ICF remains at a constant value as expected. As the flame develops, at $t \approx 1 \mathrm{~ms}$ the exothermic expansion causes a perturbation in $\chi$ for both cases and $\chi$ assumes a lower value following the thermal expansion.

Figure $3 \mathrm{~b}$ shows the evolution of $\Delta T_{Z}$, the temperature rise for a constant $Z$, in IML and ICF at $Z_{\mathrm{mr}}$ and $Z_{\mathrm{st}}$. It can be seen here that the ignition is delayed in the case of IML due to the high value of $\chi$. The delay between $Z_{\mathrm{mr}}$ and $Z_{\mathrm{st}}$ curves represents the time required for the flame spread. The close proximity of these curves for IML indicates a faster flame spread in the IML. As compared to ICF, IML has a higher $\chi$ during and postignition aiding the flame spread through increased diffusive transport. This is further elucidated in Figure 4 that shows the heat release rate (HRR) contours as a function of mixture fraction and time for ICF and IML. At ignition, there is a clear difference in HRR at $Z_{\mathrm{mr}}$ and $Z_{\mathrm{st}}$ in the case of ICF. This shows a highly localized raise in HRR and therefore temperature. In the case of IML, it takes longer to achieve the same level of heat release rate but the difference in HRR between $Z_{\mathrm{mr}}$ and $Z_{\mathrm{st}}$ is smaller and the ignition is less localized in $Z$. The increased diffusive fluxes in the case of IML

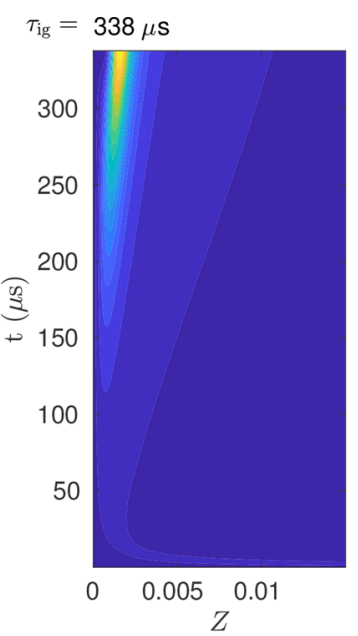

(a)

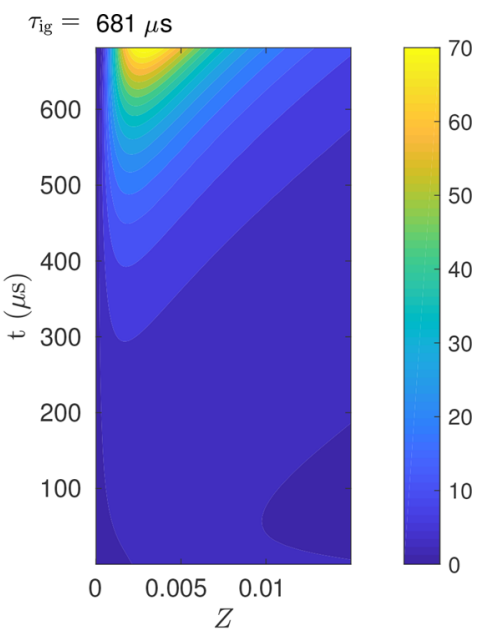

(b)
Figure 4. Comparison of heat release rate $\left(\mathrm{W} / \mathrm{m}^{3}\right)$ contours as a function of mixture fraction and time (until ignition) for (a) ICF and (b) IML. $Z_{\text {st }}=0.02$

are shown to delay the ignition by more than 2-fold as compared with ICF. The ignition in IML combines the effects of decaying $\chi$ with ignition chemistry; therefore, it mimics the situation in nonpremixed MILD burners better, which is much different from ICF.

3.1.1. Effect of $\mathrm{CO}_{2}$ on the Ignition of Biogas. The ignition of biogas under MILD conditions is estimated in IML simulations with varying levels of $\mathrm{CO}_{2}$ in the fuel. Fuel compositions containing $\mathrm{CH}_{4}$ with $\mathrm{CO}_{2}$ levels that range from $0 \%$ to $90 \%$ are considered. The $T_{\text {ox }}$ is set as $1500 \mathrm{~K}$, with an $\mathrm{O}_{2}$ mass fraction of $8 \%$ in the oxidizer. In Figure 5, two ignition

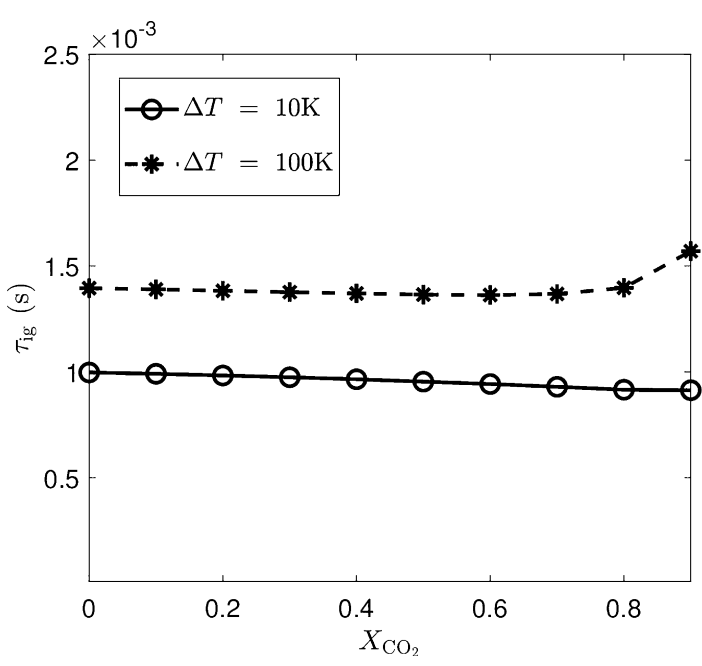

Figure 5. Ignition delay against mole fraction of $\mathrm{CO}_{2}$ in fuel.

time scales are plotted against $X_{\mathrm{CO}_{2}}$ for biogas-like fuel compositions. Ignition time scales represented here are the time for $\Delta T=10$ and $100 \mathrm{~K}$. It shows that the ignition delay remains nearly constant for $\mathrm{CO}_{2}$ levels up to $90 \%$ in the fuel. This trend is significantly different from experimentally reported ignition delays in shock tube experiments with uniform mixtures. The additional freedom of chemical species to diffuse across mixture fractions in the case of a nonpremixed flame makes ignition far less sensitive to fuel composition 
when compared with homogeneous mixtures. The numerical studies on the ignition of biogas in homogeneous mixtures show $\mathrm{CO}_{2}$ causing significant increase in ignition delays. ${ }^{40,14} \mathrm{In}$ the mixing layer, however, the influence of $\mathrm{CO}_{2}$ is nearly absent. There is actually a small decrease in $\tau_{\mathrm{ig}}$ at higher $\mathrm{CO}_{2}$ levels. After ignition $(\Delta T=10 \mathrm{~K})$, the spot of ignition develops into a flame at steady state. For $\Delta T=100 \mathrm{~K}$, the slope increases for $\mathrm{CO}_{2}$ levels above $70 \%$. This can be understood from the reduction in heat release rate due to lesser reactive content in the fuel, leading to a slower flame development.

To further explain the observed behavior, the effect of chemical and thermophysical properties of $\mathrm{CO}_{2}$ on the IML ignition delay of biogas is assessed by replacing $\mathrm{CO}_{2}$ in the fuel with the following artificial species as in ref 38

1. $\mathrm{CO}_{2} \mathrm{x}$, which is chemically inert $\mathrm{CO}_{2}$.

2. $\mathrm{CO}_{2} \mathrm{xx}$, which is $\mathrm{CO}_{2} \mathrm{x}$ with the diffusivity of methane.

3. $\mathrm{CO}_{2} \mathrm{xy}$, which is $\mathrm{CO}_{2} \mathrm{x}$ with the heat capacity of methane.

By comparing the ignition behavior of $\mathrm{CH}_{4}-\mathrm{CO}_{2} \mathrm{x}$ mixtures with $\mathrm{CH}_{4}-\mathrm{CO}_{2}$ mixtures, the influence of reactive properties of $\mathrm{CO}_{2}$ in biogas is assessed. Similarly with $\mathrm{CO}_{2} \mathrm{xx}$ and $\mathrm{CO}_{2} \mathrm{xy}$, the role of diffusivity and thermal conductivity of $\mathrm{CO}_{2}$ in the ignition of biogas is quantified. In the following analysis and Table 2, the synthetic species $\mathrm{CO}_{2} \mathrm{x}, \mathrm{CO}_{2} \mathrm{xx}$, and $\mathrm{CO}_{2} \mathrm{xy}$ replace $\mathrm{CO}_{2}$ at $30 \%$ and $90 \%$ in biogas and $\tau_{\text {ig }}$ is evaluated.

Table 2. Ignition Delay with $\mathrm{CO}_{2}$ and Artificial Species in $\mathrm{IML}$, for $T_{\mathrm{ox}}=1540 \mathrm{~K}$ and $Y_{\mathrm{O} 2, \mathrm{ox}}=0.08$

\begin{tabular}{lcccc} 
ignition delay & \multicolumn{2}{c}{$\Delta T_{\max }=10 \mathrm{~K}$} & \multicolumn{2}{c}{$\Delta T_{\max }=100 \mathrm{~K}$} \\
$X_{\mathrm{CO}_{2} \text {,fuel }}$ & $30 \%$ & $90 \%$ & $30 \%$ & $90 \%$ \\
$\mathrm{CO}_{2}(\mathrm{~ms})$ & 0.97 & 0.91 & 1.38 & 1.57 \\
$\mathrm{CO}_{2} \mathrm{x}$ & $-0.1 \%$ & $-1.2 \%$ & $-0.1 \%$ & $-3.7 \%$ \\
$\mathrm{CO}_{2} \mathrm{xx}$ & $+0.1 \%$ & $+0.1 \%$ & $+0.02 \%$ & $-3.6 \%$ \\
$\mathrm{CO}_{2} \mathrm{xy}$ & $+0.5 \%$ & $+11.3 \%$ & $+1.2 \%$ & $+39.8 \%$ \\
\hline
\end{tabular}

In Table 2 the first row shows the magnitude of ignition time scales for biogas and the following rows show the change in ignition delays corresponding to each $\mathrm{CO}_{2}$ substitute in comparison with $\mathrm{CO}_{2}$. For cases with $\mathrm{CO}_{2} \mathrm{x}$ and $\mathrm{CO}_{2} \mathrm{xx}$ the values for $\tau_{\text {ig }}$ differ only by $\approx 0.1 \%$. For $\mathrm{CO}_{2} \mathrm{x}$ the ignition delays are slightly reduced, indicating a minute inhibitory influence of the reactivity of $\mathrm{CO}_{2}$ on ignition. These results give a clear proof that the ignition delay is hardly affected by the chemical or transport properties of $\mathrm{CO}_{2}$. As $Z_{\mathrm{mr}} \approx 10^{-3}$, the $\mathrm{CO}_{2}$ content from fuel can be expected to exert no significant influence on the ignition chemistry. It has to be noted that $\tau_{\text {ig }}$ increases slightly for $30 \%$ and $90 \%$ of $\mathrm{CO}_{2} \mathrm{xy}$ in the fuel. This explains that the lower $\tau_{\text {ig }}$ at high $\mathrm{CO}_{2}$ levels are a result of the lower heat capacity of $\mathrm{CO}_{2}$ in comparison to $\mathrm{CH}_{4}$. Due to the higher $c_{p}$ of $\mathrm{CO}_{2} \mathrm{xy}$, the flame development delay until $\Delta T=100 \mathrm{~K}$ is doubled at $90 \% \mathrm{CO}_{2} \mathrm{xy}$ in comparison with $90 \% \mathrm{CO}_{2}$. In the case of $\mathrm{CO}_{2} \mathrm{xx}$ the results are much closer to $\mathrm{CO}_{2} \mathrm{x}$, showing hardly an impact of transport properties.

3.1.2. Role of Oxidizer Temperature. The influence of oxidizer temperature $\left(T_{\mathrm{ox}}\right)$ on ignition delay is assessed in a series of IMLs subsequently. For a range of $T_{\text {ox }}$ the oxidizer composition is computed at fixed values of $Y_{\mathrm{O}_{2}, \mathrm{ox}}=8 \%$, ensuring the same elemental composition. Figure 6 shows the variation of $\tau_{\text {ig }}$ within the given range of temperature. A near linear increase of $\log \left(\tau_{\mathrm{ig}}\right)$ with respect to the inverse of $T_{\mathrm{ox}}$ is

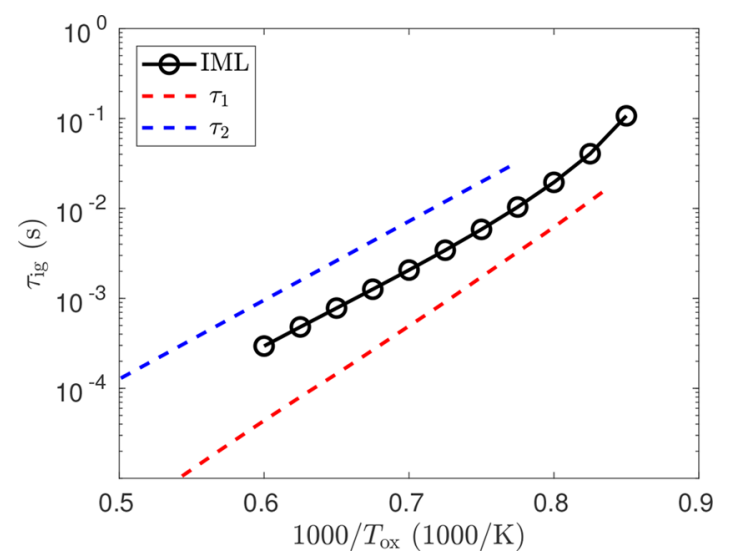

Figure 6. Ignition delay against the inverse of temperature, for $8 \%$ oxygen in the oxidizer by mass, the dashed curves represent trends based on empirical predictions.

observed. It can be noted that the slope of the curve is higher at the lowest temperatures. From shock-tube experiments of methane-oxygen mixtures in argon, an empirical correlation of ignition delay with respect to temperature is given for a range of $1200-2100 \mathrm{~K}$ as ${ }^{21}$

$$
\tau_{1}(s)=2.5 \times 10^{-15} \mathrm{e}^{(26700 / T)}\left[\mathrm{CH}_{4}\right]^{0.32}\left[\mathrm{O}_{2}\right]^{-1.02}
$$

where the concentrations of $\mathrm{CH}_{4}$ and $\mathrm{O}_{2}$ are given in moles per cubic centimeter. Equation 10 indicates a linear dependency of $\log \left(\tau_{1}\right)$ on $T^{-1}$. Furthermore, an increase in $\mathrm{O}_{2}$ concentration shortens the ignition delay and an increase in $\mathrm{CH}_{4}$ concentration increases the ignition delay. Hence, it can be expected that for a counterflow laminar flame with methane and hot oxidizer, the ignition will occur at a mixture fraction close to zero. A comparison of ignition delay trends $\left(\tau_{\text {ig }}\right.$ against $T_{\text {ox }}$ ) can be made for the IML predictions and the empirical relations such as eq 10, based on the experimental observations for homogeneous mixtures. A representative correlation based on eq 10 is given as, $\tau_{1} \propto\left[\mathrm{CH}_{4}\right]^{0.32} \mathrm{e}^{(26700 / T)}$. It is assumed here that the $\left[\mathrm{O}_{2}\right]$ at $Z_{\mathrm{mr}}$ is constant, that is, $\left[\mathrm{O}_{2}\right]_{\mathrm{mr}}=\left[\mathrm{O}_{2}\right]_{\mathrm{ox}}$. The concentration of $\mathrm{CH}_{4}$ is considered at the location of $Z_{\mathrm{mr}}$ from the unmixed initial condition. $\tau_{1}$ is plotted in Figure 6 adjacent to the $\tau_{\text {ig }}$ curve for IML using an appropriate scaling constant.

From the experiments conducted by Zeng et al., ${ }^{40}$ a second empirical correlation for $\tau_{\mathrm{ig}}$ of methane in homogeneous mixtures is given by

$$
\tau_{2}=1.31 \times 10^{-3} p^{-0.68} \mathrm{e}^{(20199 / T)}
$$

Homogeneous mixtures of methane-air were considered in this study in a temperature range of $1300-2100 \mathrm{~K}$ at a mixture equivalence ratio $\phi=0.5$. In eq $11, p$ represents the pressure in $\mathrm{MPa}$, which is atmospheric pressure in the current study. The slope of this line is given by, $\tau_{2} \propto \mathrm{e}^{(20199 / T)}$, which is lower than that of $\tau_{1}$. This trend is plotted in Figure 6, positioned above the ignition delay curve of IML. The IML ignition delay curve shows slope close to the experimentally observed value in eq 11 for most part of the temperature range considered (1300$1650 \mathrm{~K})$. Therefore, the activation temperature, $T_{\mathrm{a}}$ for IML is closer that of $\tau_{2}$. For $T_{\mathrm{ox}}<1250 \mathrm{~K}\left(1000 / T_{\mathrm{ox}}>0.8\right)$ the ignition delays are clearly seen to increase in a nonlinear fashion. This region is outside the range of experimental temperatures for $\tau_{2}$. Here onward the trend gets closer to that from eq 10 until $1200 \mathrm{~K}(1000 / T=0.83)$. Apart from similarity in trends, the magnitude of ignition delays are larger 
in the case of IML compared to the homogeneous mixtures considered here, which is caused by diffusive transport of radical species at the onset of ignition.

Figure 7 shows $Z_{\mathrm{mr}}$, the location of $\Delta T_{\max }$ in mixture fraction space at the time of ignition, against the oxidizer temperature.

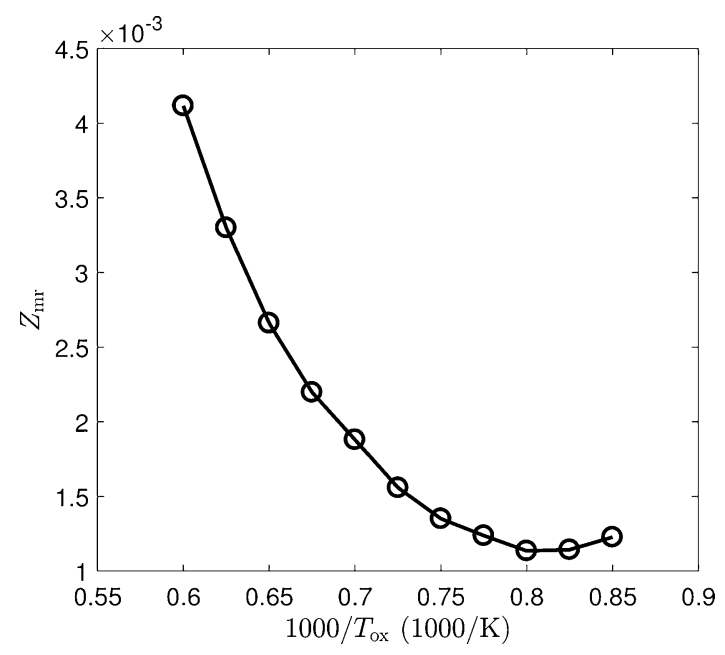

Figure 7. $Z_{\mathrm{mr}}$ with respect to $T_{\mathrm{ox}}$ for $Y_{\mathrm{O}_{2}, \mathrm{ox}}=0.08$.

It shows that $Z_{\mathrm{mr}}$ remains low within the order of $Z \approx 10^{-3}$ but varies across the range of $T_{\mathrm{ox}}$. At a high oxidizer temperature, $\tau_{\mathrm{ig}}$ is short and the scalar dissipation rates are large, leading to more diffusive transport, causing higher reactivity at $Z>10^{-3}$. For example, in Figure 4 it was seen in the case of ICF that the heat release and therefore the major reactions are concentrated over a narrow zone close to the oxidizer side, whereas in the IML, the reaction zone is widened as the reactive species are subjected to a high scalar dissipation rate. The radical species formed close to the high temperature zone are transported in the direction of fuel, widening the heat release zone and shifting the $Z_{\mathrm{mr}}$ toward $Z_{\mathrm{st}}$ compared with ICF. This shift in $Z_{\mathrm{mr}}$, however, diminishes with lower $T_{\mathrm{ox}}$. With the decrease in $T_{\mathrm{ox}}$, the reaction rates slow down leading to an increase in $\tau_{\mathrm{ig}}$. Owing to the reduction in scalar dissipation rates with the ignition delay, the $Z_{\mathrm{mr}}$ settles toward a limiting value and becomes comparable to ICF.

The ignition delay prediction for biogas compositions are shown in Figure 8 for $Y_{\mathrm{O}_{2}, \mathrm{ox}}=8 \%$ in the range of $T_{\mathrm{ox}} 1200-$ $1540 \mathrm{~K}$. Evidently, for $\mathrm{CO}_{2}$ levels from $0 \%$ to $90 \%$, the ignition delay trends and their magnitudes are hardly affected by the presence of $\mathrm{CO}_{2}$. The small change in thermal properties of the fuel is reflected in the small advancement of ignition in the case of biogas with $90 \% \mathrm{CO}_{2}$. The relative insensitivity of ignition delays to $\mathrm{CO}_{2}$ levels as observed from Figure 5 holds true for the entire range of oxidizer temperatures considered here.

3.1.3. Role of Oxygen Concentration in Oxidizer. Low levels of oxygen concentration in the oxidizer are a defining characteristic of MILD combustion. Therefore, the dependence of ignition delay with respect to oxygen levels is also investigated here. Figure 9 shows the ignition delay trends to $Y_{\mathrm{O}_{2}, \mathrm{ox}}$ of $8 \%$ and $4 \%$, for $X_{\mathrm{CO} 2}$ varying from 0 to $90 \%$ at $T_{\mathrm{ox}}=$ $1540 \mathrm{~K}$. With the oxygen level reduced to half, the ignition delays are seen to be doubled. This is in agreement with the empirical relation 10. With respect to the $\mathrm{CO}_{2}$ level, the reduction in $Y_{\mathrm{O}_{2} \text {,ox }}$ does not change the ignition delay behavior

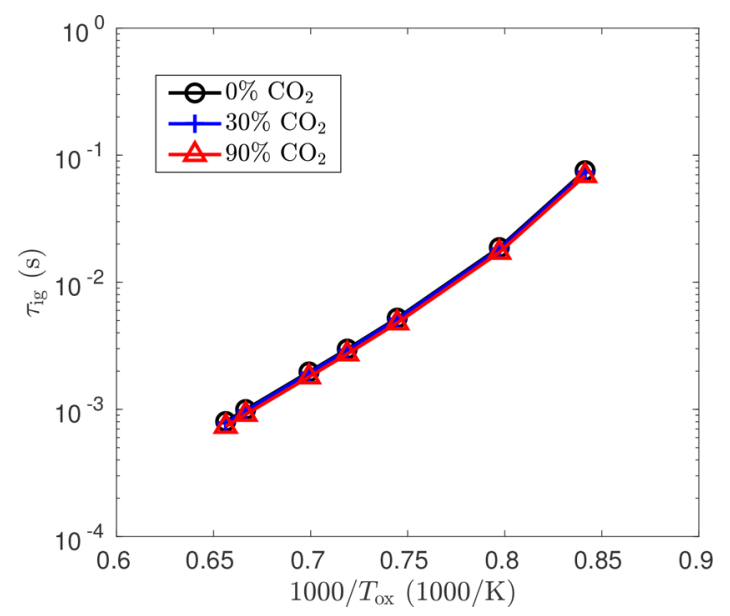

Figure 8. Ignition delay against $T_{\mathrm{ox}}$ for different levels of $\mathrm{CO}_{2}$ in fuel (methane) for $Y_{\mathrm{O}_{2}, \mathrm{ox}}=0.08$.

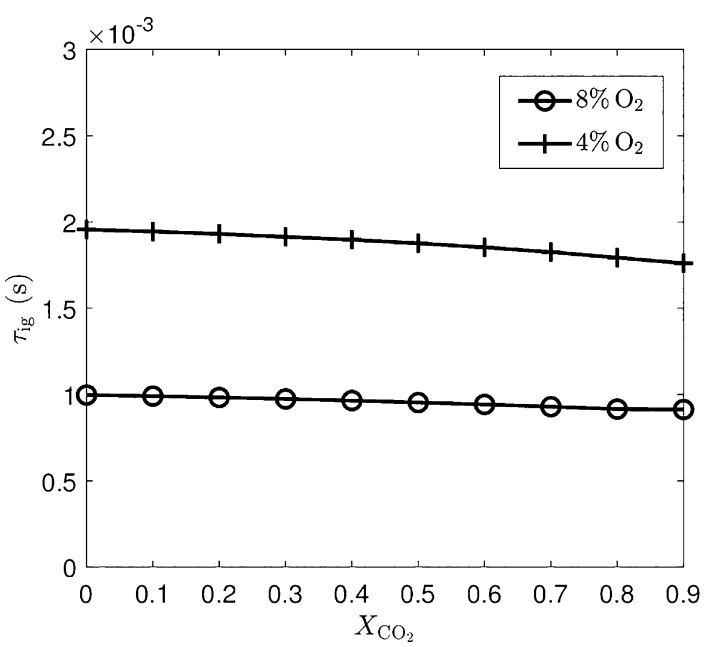

Figure 9. Ignition delay against percentage of $\mathrm{CO}_{2}$ in the fuel for $Y_{\mathrm{O}_{2}, \mathrm{ox}}=0.04$ and 0.08 with $T_{\mathrm{ox}}=1540 \mathrm{~K}$.

as from previous observations. The dependence of ignition delay on $Y_{\mathrm{O}_{2}, \mathrm{ox}}$ is investigated for oxidizer temperatures of 1200 and $1540 \mathrm{~K}$ and for oxygen mass fractions ranging from $2 \%$ to $16 \%$. The results are presented in Figure 10. For both the

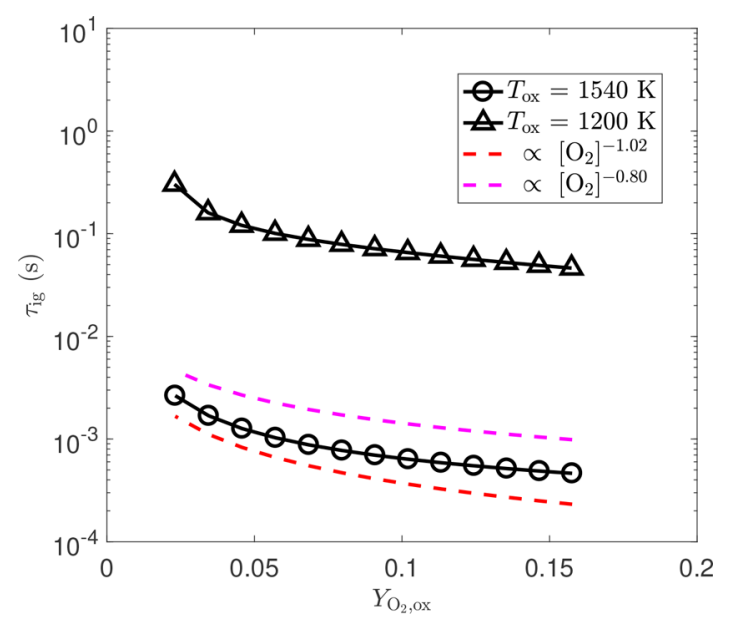

Figure 10. Ignition delay against oxygen mass fraction in the oxidizer 
oxidizer temperatures, the ignition delay curves remain parallel until the oxygen levels fall below $4 \%$. The dashed lines in Figure 10 represent trends based on empirical relations. The red line is proportional to $\left[\mathrm{O}_{2}\right]^{-1.02}$ (eq 10), and the magenta line is proportional to $\left[\mathrm{O}_{2}\right]^{-0.8}$, which is chosen to match the trend of the curves. It can be seen that, for $T_{\mathrm{ox}}=1540 \mathrm{~K}$, the red curve traces the ignition trend until $Y_{\mathrm{O} 2, \mathrm{ox}} \approx 0.04$ but shows a faster decline in $\tau_{\text {ig }}$ with increasing oxygen levels in IML. For $T_{\mathrm{ox}}=1200 \mathrm{~K}$, the ignition delay in this region increases at a higher order of $\left[\mathrm{O}_{2}\right]$ than -1.02 . At both temperatures (for oxygen levels from $4 \%$ until $16 \%$ ), the $\left[\mathrm{O}_{2}\right]^{0.8}$ curve reproduces the trend in $\tau_{\text {ig }}$ closely. Hence it can be observed that for IML the ignition delay is less sensitive to the oxygen concentration than in homogeneous mixtures and thereby causing a reduction in the order of oxygen concentration to approximately -0.8 .

3.1.4. Influence of Trace Amounts of Higher Alkanes. Biogaslike composition considered in the DJHC experiments consists of natural gas (NG) and $\mathrm{CO}_{2}$. NG was used as an affordable alternative to methane in the biogas experiments. ${ }^{32}$ The presence of trace amounts of higher alkanes in NG such as ethane and propane are known to reduce the ignition delay of methane, wherein a relatively weak carbon-carbon bond can be thermally split yielding loosely bound hydrogen atoms in the chain initiation step. ${ }^{16}$ The ignition of methane-ethane blends are studied in homogeneous mixtures by Aul et al., ${ }^{2}$ who indicated that addition of ethane to methane results in a large, nonlinear effect on reactivity and thereby ignition delays. Following ref 32, the presence of higher alkanes in NG is approximated as $3.7 \%$ ethane by volume, with the rest of the composition made of $81.3 \%$ of methane, $14.4 \%$ of nitrogen, and $0.6 \% \mathrm{CO}_{2}$. Figure 11 shows the ignition delay comparison

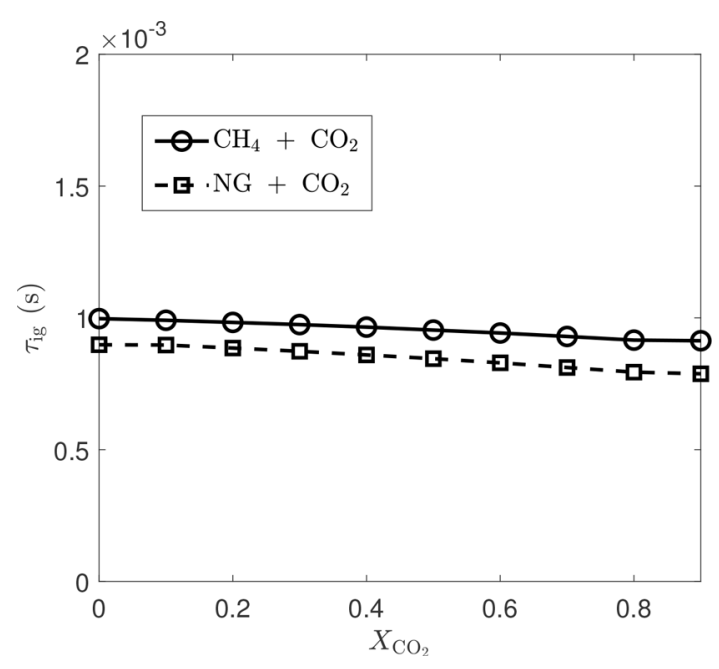

Figure 11. Comparison of $\tau_{\mathrm{ig}}$ for biogaslike compositions using natural gas instead of methane with $T_{\mathrm{ox}}=1540 \mathrm{~K}$ and $Y_{\mathrm{O}_{2}, \mathrm{ox}}=0.08$.

for methane and natural gas as the reactive component of biogas, mixed with various levels of $\mathrm{CO}_{2}$. The ignition delay for $\mathrm{NG}$ is $10 \%$ lower than $\mathrm{CH}_{4}$ due to the presence of $\mathrm{C}_{2} \mathrm{H}_{6}$, which accelerates the ignition. However, the addition of $\mathrm{CO}_{2}$ does not show a different interaction with NG than with pure methane.

Figure 12 illustrates the ignition delays in IMLs for methane and NG over the temperature range $1200-1540 \mathrm{~K}$ for $Y_{\mathrm{O}_{2}, \mathrm{ox}}$ of $8 \%$. With a modest amount of ethane present in the fuel

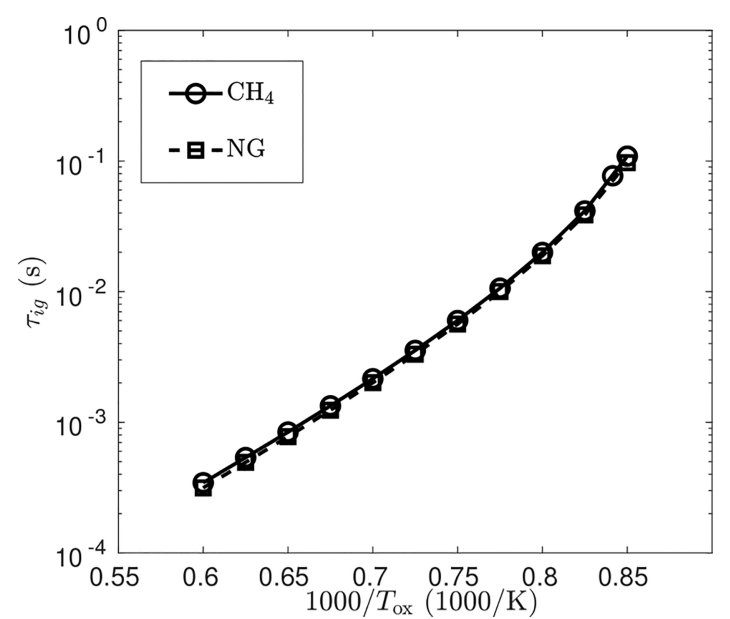

Figure 12. Comparison of $\tau_{\mathrm{ig}}$ against oxidizer temperature for methane and natural gas for $Y_{\mathrm{O}_{2}, \mathrm{ox}}=0.08$.

mixture, the ignition is advanced slightly across the range of temperatures.

3.1.5. Sensitivity Analysis. In this section, the impact of fuel bound $\mathrm{CO}_{2}$ content on ignition chemistry is examined in IML. Also the influence of oxidizer temperature on the various methane oxidation pathways is evaluated based on reaction sensitivity analysis. The sensitivity of ignition delay to oxidation chemistry of methane and biogas has been examined in previous studies ${ }^{2,40,41}$ for homogeneous mixtures at specific equivalence ratios. From these studies the influence of $\mathrm{CO}_{2}$ on ignition kinetics is seen to act in two main ways. A first effect is related to the enhancement of the reverse rate of reaction,

$$
\mathrm{CO}+\mathrm{OH} \rightleftharpoons \mathrm{CO}_{2}+\mathrm{H}
$$

consuming $\mathrm{H}$ radicals which have a positive impact on ignition. The reference to reaction, R99, stands for the corresponding number of the reaction in the GRI 3.0 mechanism. A second mode of influence is related to the increase in third body collision efficiencies. The influence of $\mathrm{CO}_{2}$ on ignition was found to be the largest for a stoichiometric mixture. In the case of IML these equivalence ratios are not isolated and therefore the influences of chemistry on ignition delay needs to be more precise. Also the impact of $\mathrm{CO}_{2}$ on ignition or the reasons for the relative absence of its influence (as seen in previous sections) are investigated. To identify the chemical reactions which are critical to the ignition of biogas in IML, a sensitivity analysis is performed. The sensitivity of ignition delay to the reaction chemistry is examined for oxidizer with $8 \% \mathrm{O}_{2}$ and at temperatures of 1200 and $1540 \mathrm{~K}$.

IML ignition delays are computed with $10 \%$ increment in individual reaction coefficient for every reaction in GRI Mech 3.0. From the results, a relative sensitivity coefficient $\sigma$ for each reaction in the mechanism is computed as

$$
\sigma_{r}=\frac{k_{r}}{\tau_{\text {ig }}} \frac{\Delta \tau_{\text {ig }}}{\Delta k_{r}}=\frac{1}{\tau_{\text {ig }}} \frac{\tau_{\text {ig }}\left(r_{k}\right)-\tau_{\text {ig }}}{0.1}
$$

where $\tau_{\text {ig }}\left(r_{k}\right)$ stands for the ignition delay corresponding to a $10 \%$ increase in the reaction rate constant $k$ for reaction $r_{k}$. A negative value of $\sigma$ points to enhancement of ignition and a positive $\sigma$ denotes an inhibitory effect of the reaction. Figure 13 shows the most sensitive reactions in IMLs plotted for fuels $\mathrm{CH}_{4}$ and $\mathrm{CH}_{4}-\mathrm{CO}_{2}(90 \%)$ corresponding to $T_{\mathrm{ox}}=$ (a) 1200 and (b) $1540 \mathrm{~K}$. It can be seen that the ignition delay becomes 


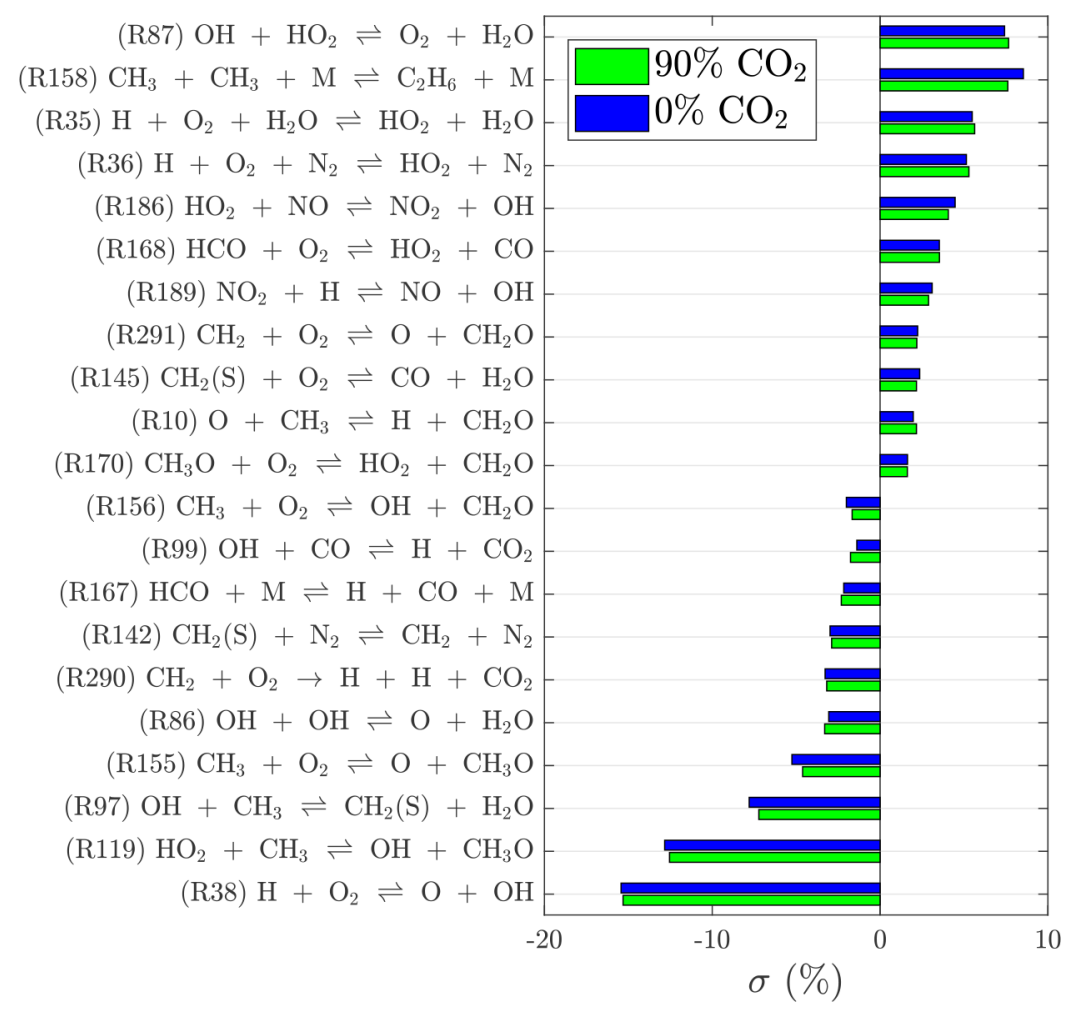

(a) $T_{\mathrm{ox}}=1200 \mathrm{~K}$

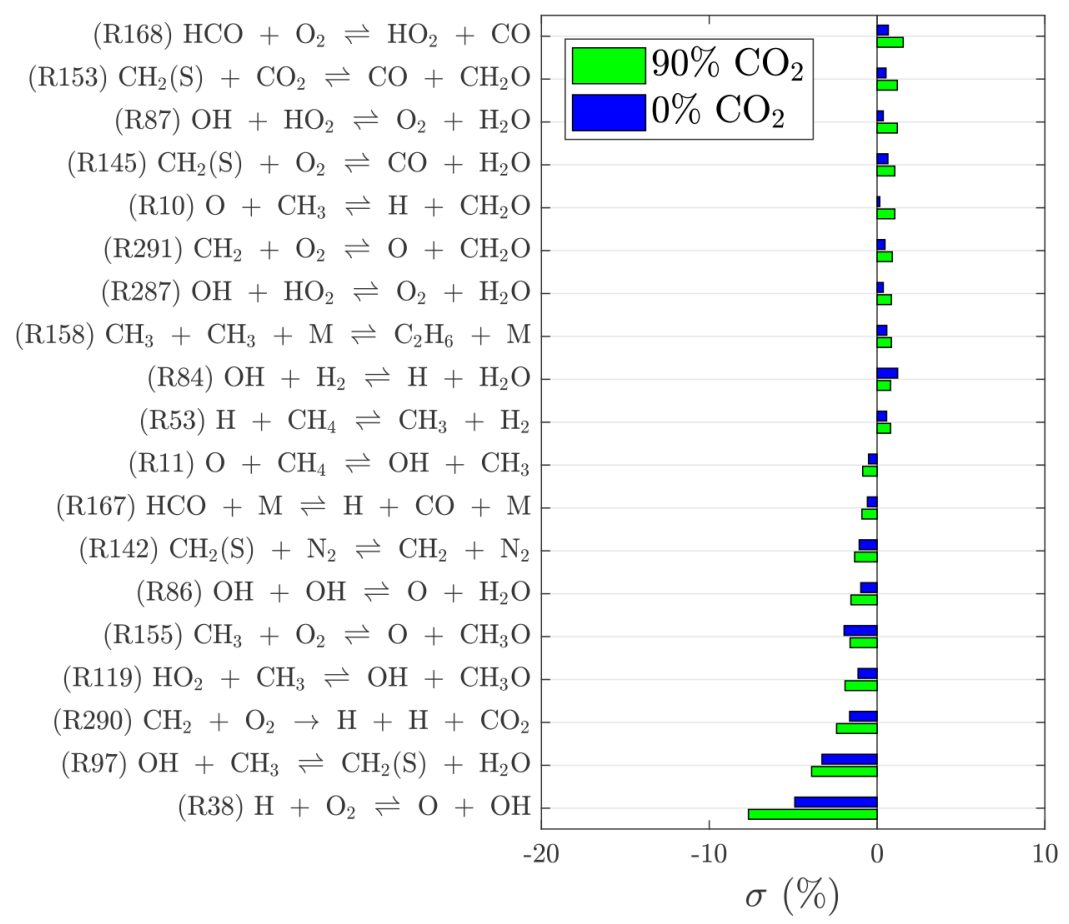

(b) $T_{\text {ox }}=1540 \mathrm{~K}$

Figure 13. Relative sensitivity of $\tau_{\text {ig }}$ for methane and biogas with $90 \% \mathrm{CO}_{2}$.

much more sensitive to reactions at lower temperatures. The reason for this drop in $\sigma$ at high temperatures is the presence of higher amounts of $\mathrm{H}, \mathrm{OH}$, and $\mathrm{O}$ radicals, which play the main role in chain branching reactions that enhance ignition. Therefore, a $10 \%$ change in the most important chain branching reaction in the ignition of alkanes, $\mathrm{R} 38^{4}$ 


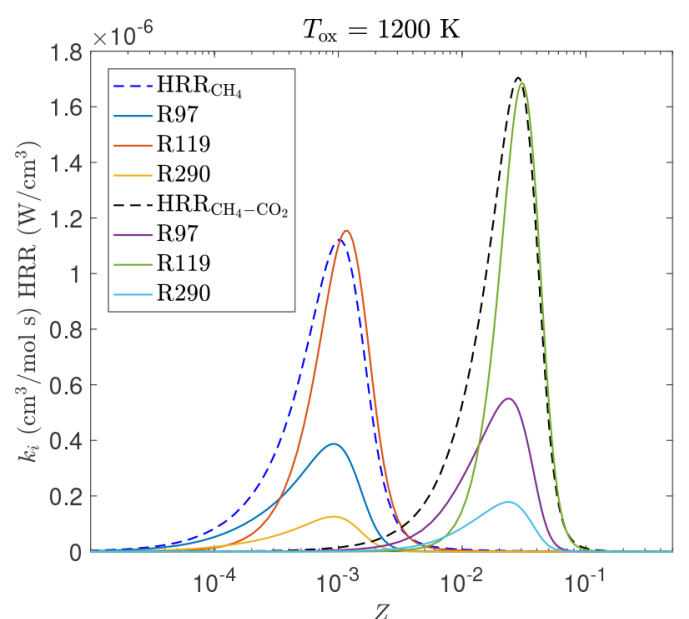

(a)

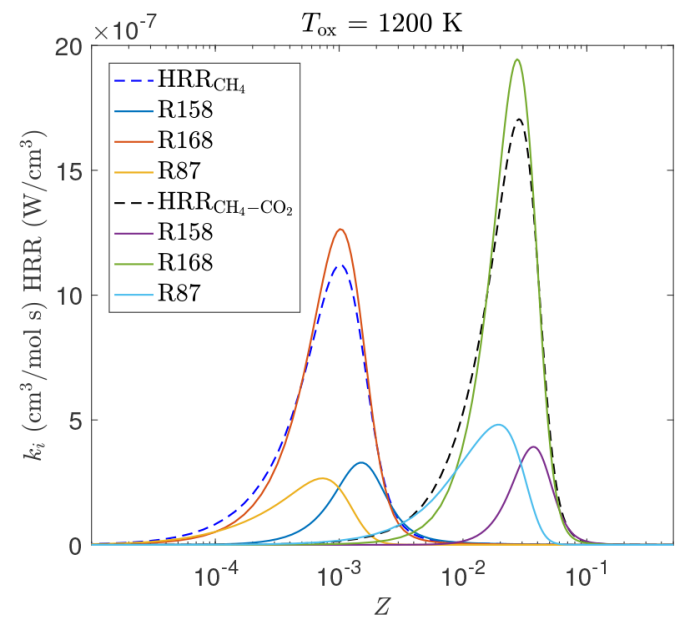

(c)

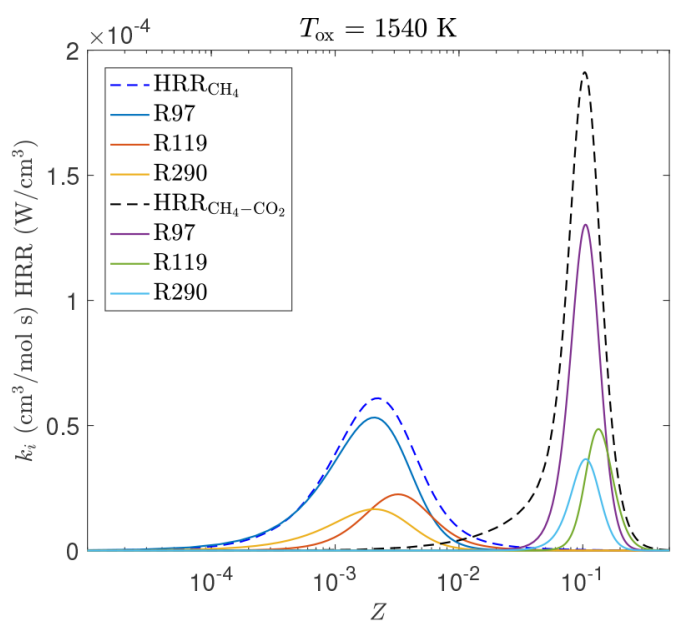

(b)

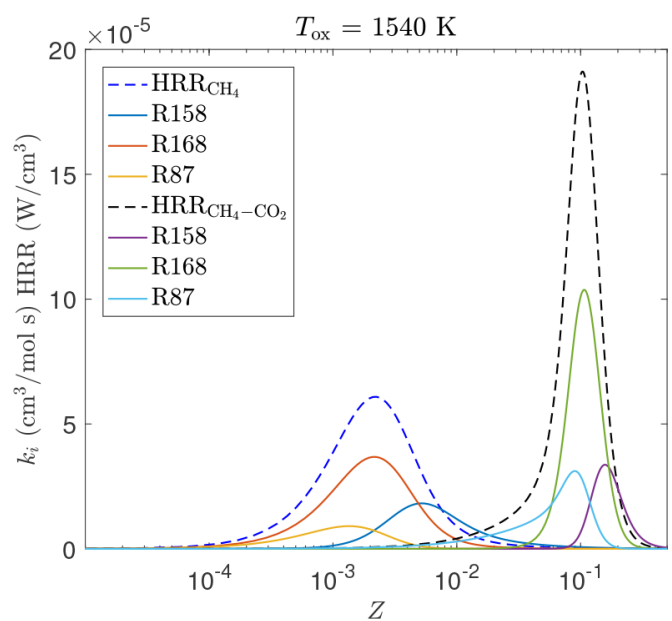

(d)

Figure 14. Reaction rates of selected ( $\mathrm{a}, \mathrm{b})$ ignition promoting reactions and $(\mathrm{c}, \mathrm{d})$ ignition inhibiting reactions in IML at $t=\tau_{\mathrm{ig}}$. The instantaneous heat release rates are plotted in dashed lines.

$$
\mathrm{H}+\mathrm{O}_{2} \rightleftharpoons \mathrm{O}+\mathrm{OH}
$$

results in less than $10 \%$ change in the ignition delay. Therefore, the role of chemistry to rise temperature by $10 \mathrm{~K}$ is relatively lower than in case of a low temperature mixture. Furthermore, it can be seen that for the range of temperatures considered, $\mathrm{R} 99$, a critical reaction that is important in homogeneous mixtures of biogas, has no notable influence on the ignition delay. This could be due to the fact that despite containing $90 \% \mathrm{CO}_{2}$ in the fuel, at $Z_{\mathrm{mr}}$ the $\mathrm{CO}_{2}$ levels are not high enough to cause a reversal in reaction $\mathrm{R} 99$.

Considering the third body collision efficiency aspect of $\mathrm{CO}_{2}$, Fischer and Jiang ${ }^{14}$ found that the thermal decomposition of methane by means of reaction

$$
\mathrm{CH}_{4}+\mathrm{M} \rightleftharpoons \mathrm{CH}_{3}+\mathrm{H}+\mathrm{M}
$$

becomes crucial for rich homogeneous mixtures in the presence of $\mathrm{CO}_{2}$. In the case of IMLs, however, this reaction shows very low sensitivity, $(\sigma<0.3 \%$, this reaction is therefore not included in the figures comparing the sensitivity coefficients) as again $Z_{\mathrm{mr}}$ is situated in an ultralean region in mixture fraction space. Hence the presence of $\mathrm{CO}_{2}$ is seen to be irrelevant on ignition kinetics.
Further, the response of oxidation steps for methane to the oxidizer temperature is addressed. It can be seen from Figure 13 that the chain branching reaction $\mathrm{R} 38$, which plays the most important role in ignition, promotes ignition at $T_{\mathrm{ox}}=1540$ and $1200 \mathrm{~K}$. The instantaneous rates for major reactions inhibiting and promoting ignition are plotted as a function of $Z$ in Figure 14 for both fuels under consideration. Although it does not provide direct information on the history of reactions, it gives insight into the reaction rates at the time of ignition indicating the fuels' stage of oxidation. It can be noted that at $1200 \mathrm{~K}$ the heat release is of much lower magnitude and takes place at much lower mixture fraction than for $1540 \mathrm{~K}$. As previously discussed in section 3.1.2, this effect is caused by the scalar dissipation decay in IML. Also methane shows ignition closer to the oxidizer than biogas (with $10 \%$ methane). The reduced availability of methane shifts the heat release to a region away from the oxidizer.

In the $\mathrm{C}_{1}$ branch for the oxidation of methane, two reaction paths exist for the conversion of $\mathrm{CH}_{3}$ into $\mathrm{CO}_{2}^{21,38}$

$$
\begin{aligned}
& \mathrm{CH}_{3} \rightarrow \mathrm{CH}_{3} \mathrm{O} \rightarrow \mathrm{CH}_{2} \mathrm{O} \rightarrow \mathrm{HCO} \rightarrow \mathrm{CO} \rightarrow \mathrm{CO}_{2} \\
& \mathrm{CH}_{3} \rightarrow \mathrm{CH}_{2}(\mathrm{~s}) \rightarrow \mathrm{CH}_{2} \rightarrow \mathrm{HCO} \rightarrow \mathrm{CO} \rightarrow \mathrm{CO}_{2}
\end{aligned}
$$


R97 and R119, which are among the most ignition promoting reactions in Figure 13, mark the distinct reaction lines for $\mathrm{CH}_{3}$.

$$
\begin{aligned}
& \mathrm{OH}+\mathrm{CH}_{3} \rightleftharpoons \mathrm{CH}_{2}(\mathrm{~S})+\mathrm{H}_{2} \mathrm{O} \\
& \mathrm{HO}_{2}+\mathrm{CH}_{3} \rightleftharpoons \mathrm{OH}+\mathrm{CH}_{3} \mathrm{O}
\end{aligned}
$$

Figure 13 shows the instantaneous rates of R97 and R119 at ignition. From the plots, the reaction rate of R119 is higher than R97 at $1200 \mathrm{~K}$ for both fuels. The sensitivity coefficients show that ignition is highly promoted by R119 at $1200 \mathrm{~K}$, in comparison to which $\mathrm{R} 97$ shows a lower ignition promoting effect. R119 is known to be the dominant oxidation step for methyl radical close to ignition, ${ }^{21,41}$ producing the dominant chain branching radical $\mathrm{OH}$ and $\mathrm{CH}_{3} \mathrm{O}$, at the same timeconsuming $\mathrm{HO}_{2}$. As for homogeneous mixtures, this reaction is shown to be highly ignition promoting. ${ }^{41}$ R119 competes with the chain termination reactions, R87 and R158

$$
\begin{aligned}
& \mathrm{OH}+\mathrm{HO}_{2} \rightleftharpoons \mathrm{O}_{2}+\mathrm{H}_{2} \mathrm{O} \\
& \mathrm{CH}_{3}+\mathrm{CH}_{3}+\mathrm{M} \rightleftharpoons \mathrm{C}_{2} \mathrm{H}_{6}+\mathrm{M}
\end{aligned}
$$

competing for $\mathrm{HO}_{2}$ and $\mathrm{CH}_{3}$, respectively. The highest ignition inhibiting effect (largest positive values of $\sigma$ ) for R87 and R158 at $1200 \mathrm{~K}$ highlights the significance of reaction R119 in the case of IML as well. Furthermore, the ignition inhibiting reactions mainly show one characteristic, that is the formation of $\mathrm{HO}_{2}$, feeding reaction $\mathrm{R} 87$ at $1200 \mathrm{~K}$.

The ignition promoting reactions with highest $\sigma$ indicate dominance of the second reaction line in the $\mathrm{C} 1 \mathrm{branch}$. At $T_{\mathrm{ox}}$ $=1540 \mathrm{~K}, \mathrm{R} 97$ has a higher reaction rate than R119 and has a higher ignition promoting effect in comparison. Here the inhibitory effect of chemistry on ignition becomes much smaller in general and the inhibitory influence of $\mathrm{HO}_{2}$ forming reactions are seen to be diminished. Further down the pathway, reaction R290

$$
\mathrm{CH}_{2}+\mathrm{O}_{2} \rightleftharpoons \mathrm{H}+\mathrm{H}+\mathrm{CO}_{2}
$$

shows maximum sensitivity. Furthermore, Figure 14a, b shows that the peaks of R97 and R290 are aligned at both temperatures to the HRR peak, whereas the peak of R119 is offset to the richer side at high temperature. At high temperatures, shorter $\tau_{\text {ig }}$ cause ignition to occur under high $\chi$ (Figure 7), which favors diffusion to the richer side, hence shifting the peaks of reactive species. Here R97 shows lesser influence of $\chi$ as compared to R119. This suggests that R97 is a more significant route of oxidation for methyl radical at high temperature and scalar dissipation rate.

The subsequent oxidation of $\mathrm{CH}_{2}(\mathrm{~S})$ results in the formation of formyl radical and its conversion to $\mathrm{CO}$ could take place following the reaction pathways R167 and R168, ${ }^{36}$

$$
\begin{aligned}
& \mathrm{HCO}+\mathrm{M} \rightleftharpoons \mathrm{H}+\mathrm{CO}+\mathrm{M} \\
& \mathrm{HCO}+\mathrm{O}_{2} \rightleftharpoons \mathrm{HO}_{2}+\mathrm{CO}
\end{aligned}
$$

Figure 13b shows that R167 promotes ignition whereas R168 has a high inhibitory effect on ignition as it produces the chain terminating radical $\mathrm{HO}_{2}$. Figure $14 \mathrm{c}$, d shows that R168 has a higher reaction rate than R158 and R87 which are the most ignition inhibiting reactions at $1200 \mathrm{~K}$. The relative increase in the influence of $\mathrm{HCO}$ oxidation at $1540 \mathrm{~K}$ suggests that the ignition is more sensitive to the terminal steps of methyl oxidation at high temperatures.

From the observations comparing ignition chemistry at 1200 and $1540 \mathrm{~K}$ in Figure 14, it can be suggested that following the main chain branching reaction $\mathrm{R} 38$, at $1200 \mathrm{~K}$ the ignition is promoted by the methyl oxidation route R119 and inhibited by R87 and R158. R97 promotes ignition better at $1540 \mathrm{~K}$ and the inhibitory effect of $\mathrm{HO}_{2}$ producing reactions on ignition are at bare minimum here. The shift in the most sensitive reaction pathways across temperatures indicates the stage of flame development at which ignition is attained. In the case of IML, for both oxidizer temperatures considered, the influence of $\mathrm{CO}_{2}$ on ignition sensitivity can be attributed to the heat capacity of $\mathrm{CO}_{2}$ rather than its chemical depletion of the $\mathrm{O} / \mathrm{H}$ radical pool which is critical for ignition as seen in homogeneous mixtures. Therefore, it is shown here that fuel bound $\mathrm{CO}_{2}$ is irrelevant to the ignition chemistry. The sensitivity coefficients for methane oxidation steps show that in a nonpremixed environment the reaction pathways changes their sensitivities with respect to the oxidizer temperature.

\section{CONCLUSION}

The ignition of methane and biogas in unsteady reactiondiffusion layers (IML) was investigated. In contrast with previous studies on the ignition of biogas in homogeneous mixtures, ${ }^{14}$ the current study shows that the addition of $\mathrm{CO}_{2}$ has little influence on ignition delay in nonpremixed mode. The largest influence of $\mathrm{CO}_{2}$ addition is found in the flame spreading rate, that is, an increment in $\mathrm{CO}_{2}$ level leads to a slower growth of the flame across the mixture fraction space. The differences between the ignition in a spatial mixing layer and a counterflow setup are also studied. Against ICF, IML shows increased ignition delay due to high initial scalar dissipation rate. It is shown in the results that in a nonpremixed MILD environment, the properties of the hot oxidizer impart a far more significant influence on ignition delay than the inert components in biogas. A sensitivity analysis of ignition delay with respect to $\mathrm{CO}_{2}$ levels in biogas shows weak relative sensitivity with respect to reactions involving any of the fuel components.

The results from the current study are important for modeling turbulent MILD combustion of biogas. This holds especially for of a Jet-in-Hot-Coflow burner where the turbulent mixing of fuel with the hot coflow leads to pockets of ignition, which stabilizes the flame. With respect to MILD combustion in practical applications, further investigation is required to understand the role of product recirculation, interaction of multiple mixing layers, higher dimensional effects, and turbulence on the ignition of biogas in nonpremixed systems. The influence of turbulence on nonpremixed ignition was reviewed by Mastorakos. ${ }^{23}$ An increase in the $\mathrm{CO}_{2}$ content in biogas increases $Z_{\mathrm{mr}}$ and, therefore, may enhance the effects of turbulence on ignition. The results from the current IML study helps in explaining the experimental findings in DJHC experiments with biogas, that a higher level of $\mathrm{CO}_{2}$ in the fuel may not affect the ignition delay and thereby the lift-off height of the flame.

\section{ASSOCIATED CONTENT}

\section{S Supporting Information}

The Supporting Information is available free of charge on the ACS Publications website at DOI: 10.1021/acs.energyfuels. 8 b01388.

Table of oxidizer boundary conditions as mentioned in the text (PDF) 


\section{AUTHOR INFORMATION}

\section{Corresponding Author}

*E-mail: a.vasavan@tue.nl.

\section{ORCID}

Aromal Vasavan: 0000-0002-1010-0828

\section{Notes}

The authors declare no competing financial interest.

\section{ACKNOWLEDGMENTS}

We gratefully acknowledge the financial support provided by The Netherlands Organisation for Scientific Research (NWO) for conducting the current study.

\section{NOMENCLATURE}

$a=$ strain rate

$c_{p}=$ specific heat capacity

$D=$ scalar diffusivity

$G=$ tangential velocity gradient

$i=$ index of chemical species

$k_{r}=$ reaction rate

$M=$ atomic mass

$N_{\text {sp }}=$ total number of species

$p=$ pressure

$t=$ time

$T=$ temperature

$T_{\mathrm{ox}}=$ oxidizer temperature

$U_{i}=$ diffusion velocity

$w_{i}=$ net chemical production rate

$X_{i}=$ species mole fraction

$Y_{\mathrm{O}_{2}, \mathrm{ox}}=$ oxygen mass fraction in the oxidizer

$Y_{i}=$ species mass fraction

$Z=$ mixture fraction

$Z_{\mathrm{mr}}=$ most reactive mixture fraction

$Z_{\text {st }}=$ stoichiometric mixture fraction

$\Delta T=$ temperature rise

$\Delta T_{Z}=$ temperature rise along a constant mixture fraction

erfc $=$ complementary error function

$\chi=$ scalar dissipation rate

$\delta=$ mixing layer thickness

$\lambda=$ thermal conductivity

$\mu=$ viscosity

$\rho=$ density

$\rho_{\text {ox }}=$ oxidizer density

$\sigma_{r}=$ relative sensitivity

$\tau_{\mathrm{ig}}=$ ignition delay

\section{REFERENCES}

(1) Abtahizadeh, E.; De Goey, P.; Van Oijen, J. Development of a novel flamelet-based model to include preferential diffusion effects in autoignition of $\mathrm{CH} 4 / \mathrm{H} 2$ flames. Combust. Flame 2015, 162 (11), $4358-4369$.

(2) Aul, C. J.; Metcalfe, W. K.; Burke, S. M.; Curran, H. J.; Petersen, E. L. Ignition and kinetic modeling of methane and ethane fuel blends with oxygen: A design of experiments approach. Combust. Flame 2013, 160 (7), 1153-1167.

(3) Bari, S. Effect of carbon dioxide on the performance of biogas/ diesel duel-fuel engine. Renewable Energy 1996, 9 (1), 1007-1010.

(4) Cavaliere, A.; De Joannon, M. Mild combustion. Prog. Energy Combust. Sci. 2004, 30 (4), 329-366.

(5) Cavicchi, B. Sustainability that backfires: the case of biogas in emilia romagna. Environ. Innovation Soc. Trans. 2016, 21, 13-27.
(6) Chen, S.; Zheng, C. Counterflow diffusion flame of hydrogenenriched biogas under $\{$ MILD $\}$ oxy-fuel condition. Int. J. Hydrogen Energy 2011, 36 (23), 15403-15413.

(7) Coelho, P.; Peters, N. Numerical simulation of a mild combustion burner. Combust. Flame 2001, 124 (3), 503-518.

(8) Coriton, B.; Frank, J. H.; Gomez, A. Effects of strain rate, turbulence, reactant stoichiometry and heat losses on the interaction of turbulent premixed flames with stoichiometric counterflowing combustion products. Combust. Flame 2013, 160 (11), 2442-2456.

(9) Dally, B. B.; Karpetis, A. N.; Barlow, R. S. Structure of turbulent non-premixed jet flames in a diluted hot coflow. Proc. Combust. Inst. 2002, 29 (1), 1147-1154.

(10) de Joannon, M.; Sabia, P.; Cozzolino, G.; Sorrentino, G.; Cavaliere, A. Pyrolitic and oxidative structures in hot oxidant diluted oxidant (hodo) mild combustion. Combust. Sci. Technol. 2012, 184 (7-8), 1207-1218.

(11) de Joannon, M.; Sorrentino, G.; Cavaliere, A. Mild combustion in diffusion-controlled regimes of hot diluted fuel. Combust. Flame 2012, 159 (5), 1832-1839.

(12) Doan, N. A. K.; Swaminathan, N.; Minamoto, Y. DNS of MILD combustion with mixture fraction variations. Combust. Flame 2018, 189, 173-189.

(13) Evans, M. J.; Medwell, P. R.; Tian, Z. F.; Frassoldati, A.; Cuoci, A.; Stagni, A. Ignition Characteristics in Spatially Zero-, One- and Two-Dimensional Laminar Ethylene Flames. AIAA J. 2016, 54 (10), 3255-3264.

(14) Fischer, M.; Jiang, X. An investigation of the chemical kinetics of biogas combustion. Fuel 2015, 150, 711-720.

(15) Gerstein, M. The structure of laminar flames. Symp. (Int.) Combust., [Proc.] 1953, 4 (1), 35-43.

(16) Healy, D.; Curran, H. J.; Simmie, J. M.; Kalitan, D. M.; Zinner, C. M.; Barrett, A. B.; Petersen, E. L.; Bourque, G. Methane/ethane/ propane mixture oxidation at high pressures and at high, intermediate and low temperatures. Combust. Flame 2008, 155 (3), 441-448.

(17) Holm-Nielsen, J.; Al Seadi, T.; Oleskowicz-Popiel, P. The future of anaerobic digestion and biogas utilization. Bioresour. Technol. 2009, 100 (22), 5478-5484.

(18) Iovane, P.; Nanna, F.; Ding, Y.; Bikson, B.; Molino, A. Experimental test with polymeric membrane for the biogas purification from co2 and h2s. Fuel 2014, 135, 352-358.

(19) Knikkerr, R.; Dauptain, A.; Cuenot, B.; Poinsot, T. Comparison of computational methodologies for ignition of diffusion layers. Combust. Sci. Technol. 2003, 175 (10), 1783-1806.

(20) Kreutz, T. G.; Law, C. K. Ignition in nonpremixed counterflowing hydrogen versus heated air: Computational study with skeletal and reduced chemistry. Combust. Flame 1998, 114 (34), 436-456.

(21) Law, C. K. Combustion Physics; Cambridge University Press, 2006.

(22) Liñán, A.; Williams, F. A. Ignition in an unsteady mixing layer subject to strain and variable pressure. Combust. Flame 1993, 95 (12), 31-46.

(23) Mastorakos, E. Ignition of turbulent non-premixed flames. Prog. Energy Combust. Sci. 2009, 35 (1), 57-97.

(24) Muzio, L.; Quartucy, G. Implementing nox control: Research to application. Prog. Energy Combust. Sci. 1997, 23 (3), 233-266.

(25) Oldenhof, E. Autoignition and flame stabilisation processes in turbulent non-premixed hot coflow flames. Ph.D. thesis, TUDelft, 2012.

(26) Oldenhof, E.; Tummers, M.; van Veen, E.; Roekaerts, D. Ignition kernel formation and lift-off behaviour of jet-in-hot-coflow flames. Combust. Flame 2010, 157 (6), 1167-1178.

(27) Oldenhof, E.; Tummers, M. J.; van Veen, E. H.; Roekaerts, D. J. Ignition kernel formation and lift-off behaviour of jet-in-hot-coflow flames. Combust. Flame 2010, 157 (6), 1167-1178.

(28) Oldenhof, E.; Tummers, M. J.; van Veen, E. H.; Roekaerts, D. J. E. M. Role of entrainment in the stabilisation of jet-in-hot-coflow flames. Combust. Flame 2011, 158 (8), 1553-1563. 
(29) Peters, N. Turbulent Combustion. Cambridge Monographs on Mechanics; Cambridge University Press, 2000.

(30) Pitsch, H.; Peters, N. Investigation of the Ignition Process of Sprays Under Diesel Engine Conditions Using Reduced n-Heptane Chemistry. SAE (724), 982464. SAE Tech. Pap. Ser. 1998, DOI: $10.4271 / 982464$.

(31) Qian, Y.; Sun, S.; Ju, D.; Shan, X.; Lu, X. Review of the state-ofthe-art of biogas combustion mechanisms and applications in internal combustion engines. Renewable Sustainable Energy Rev. 2017, 69, 5058.

(32) Sarras, G.; Mahmoudi, Y.; Arteaga Mendez, L. D.; Van Veen, E. H.; Tummers, M. J.; Roekaerts, D. J. Modeling of turbulent natural gas and biogas flames of the delft jet-in-hot-coflow burner: Effects of coflow temperature, fuel temperature and fuel composition on the flame lift-off height. Flow. Flow, Turbul. Combust. 2014, 93 (4), 607635.

(33) Sidey, J. A.; Giusti, A.; Mastorakos, E. Simulations of laminar non-premixed flames of kerosene with hot combustion products as oxidiser. Combust. Theory Modell. 2016, 20 (5), 958-973.

(34) Smith, G. P.; Golden, D. M.; Frenklach, M.; Moriarty, N. W.; Eiteneer, B.; Goldenberg, M.; Bowman, C. T.; Hanson, R. K.; Song, S.; Gardiner, W. C., Jr.; Lissianski, V. V.; Qin, Z. http://www.me. berkeley.edu/gri mech/ (accessed August 3, 3018).

(35) Somers, $\bar{L}$. The simulation of flat flames with detailed and reduced chemical models. Eindhoven University of Technology, PhD Thesis, Eindhoven, The Netherlands, 1994.

(36) Timonen, R. S.; Ratajczak, E.; Gutman, D. Kinetics of the reactions of the formyl radical with oxygen, nitrogen dioxide, chlorine, and bromine. J. Phys. Chem. 1988, 92 (3), 651-655.

(37) Van Oijen, J. A. Direct numerical simulation of autoigniting mixing layers in MILD combustion. Proc. Combust. Inst. 2013, 34 (1), $1163-1171$.

(38) Wang, L.; Liu, Z.; Chen, S.; Zheng, C.; Li, J. Physical and Chemical Effects of $\mathrm{CO}_{2}$ and $\mathrm{H}_{2} \mathrm{O}$ Additives on Counterflow Diffusion Flame Burning Methane. Energy Fuels 2013, 27 (12), 76027611.

(39) Wünning, J. Flameless oxidation to reduce thermal noformation. Prog. Energy Combust. Sci. 1997, 23 (1), 81-94.

(40) Zeng, W.; Ma, H.; Liang, Y.; Hu, E. Experimental and modeling study on effects of N2and CO2on ignition characteristics of methane/ air mixture. Journal of Advanced Research 2015, 6 (2), 189-201.

(41) Zhang, Y.; Huang, Z.; Wei, L.; Zhang, J.; Law, C. K. Experimental and modeling study on ignition delays of lean mixtures of methane, hydrogen, oxygen, and argon at elevated pressures. Combust. Flame 2012, 159 (3), 918-931. 